\title{
Thermodynamics of indirect water injection in internal combustion engines: theoretical assessment of the fresh mixture cooling effect
}

\author{
A. VAUDREY* ${ }^{*}, 1,2$ \\ ${ }^{1}$ Université de Lyon, ECAM Lyon, INSA-Lyon, LabECAM, F-69005, France. \\ ${ }^{2}$ Pontificia Universidad Católica del Peru (PUCP), Laboratorio de Energía, Lima, Peru.
}

October 18, 2017

\begin{abstract}
Water injection is a well-known efficient way to improve the performance of internal combustion engines. Amazingly, most of previous studies have yet only assess this process in an experimental manner, depriving us of an understanding of its specific influence on different operating phases of the engine - density of the aspirated fresh mixture, work required by the compression stroke, and so on - but also of the possibility to predict its effects if set up on an existing engine. Thanks to a theoretical framework specifically developed, and similar to the one commonly used for the analysis of air conditioning systems, we start in this paper to untangle in a theoretical manner the different consequences of water injection on internal combustion engines. This first study is specifically focused on the fresh mixture density increase, due to the vaporisation of liquid water in the intake manifold. Results show that, in the best scenarios, we cannot expect to increase the amount of fuel finally aspirated into the cylinders by more than $10 \%$. The methodology presented here, as well as the python software specifically developed, can be of a precious help for the optimisation of such process if applied to existing or future engines.
\end{abstract}

PACS numbers : 88.05.Bc, 88.05.De, 88.05.Xj, 92.60.Sz

Keywords : Internal Combustion Engines, Water Injection, Intake fumigation, Fogging

*Corresponding author : alexandre.vaudrey@ecam.fr, ORCID iD: 0000-0002-8613-774X 


\section{Contents}

1. Introduction 2

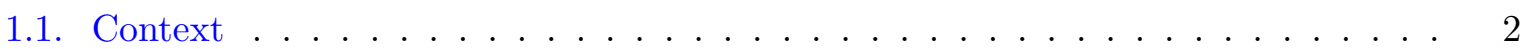

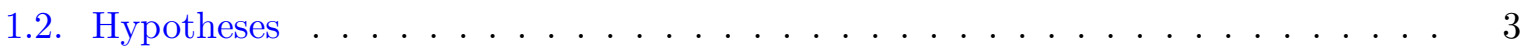

2. Water injection in internal combustion engines 4

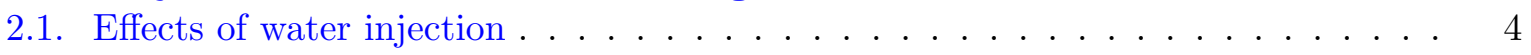

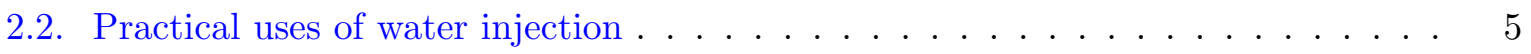

3. Thermodynamics of humid fresh mixtures 5

3.1. Mass balance of the water injection process . . . . . . . . . . . 5

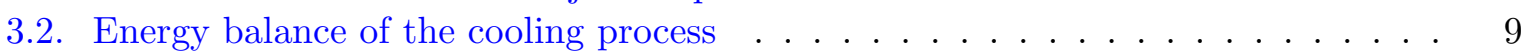

3.3. Complete vaporisation . . . . . . . . . . . . . . . . . . . . . 10

3.4. Incomplete vaporisation . . . . . . . . . . . . . . . . 10

3.5. Cooling effect and wet-bulb temperature . . . . . . . . . . . . . 12

3.6. Intake valve temperature . . . . . . . . . . . . . . . . . . . 14

3.7. Consequences on the amount of fresh mixture aspirated . . . . . . . . . . . 14

4. Results and discussion 15

4.1. Spark ignited engine fed by pure octane . . . . . . . . . . . . . . 16

4.2. Compression ignited engine fed by pure cetane . . . . . . . . . . . . 19

5. Conclusions 19

$\begin{array}{ll}\text { A. The water injection python package } & 21\end{array}$

A.1. Introduction . . . . . . . . . . . . . . . . . . . 21

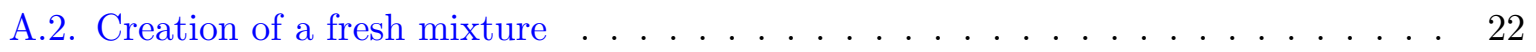

A.3. Other parameters and first results . . . . . . . . . . . . . . 22

\section{Introduction}

\subsection{Context}

Internal Combustion Engine (ICE) is by far the most widespread of all prime movers, i.e. primary sources of mechanical power. According to several authors $[1,2]$, this situation is probably not about to change, at least in the short run. However, in order to keep up being so helpful to mankind, ICE has to overcome at least two formidable challenges.

The first one is related to the fuels such engines consume, predominantly of a fossil and then non sustainable nature ${ }^{1}$. The second challenge ICE has to overcome is the control of its polluting emissions, including green house gases, nitrogen oxides and fine particles, whom daily consequences are already of a concrete and hazardous nature for a lot of us. ICE has thus to evolve in order to do its usual duty more cleanly and from a wider range of different fuels $[2,4,5]$.

Because it helps to improve its performance and to decrease some of its polluting emissions, water injection (WI) is an old, well-known, but still promising solution that can help ICE in its quest for improvement $[6,7]$. Most of previous studies of the effects of WI on ICE have been yet almost only based on experimental results, and are then partially ineffective to untangle its actual effects on different phases of the engine. For example, what is fresh mixture density increase we can expect from such process? By how much does it decreases the mechanical work consumed by the compression stroke? What are its consequences on the efficiency of the whole engine cycle? What is the optimal amount of water to inject in the intake manifold?

\footnotetext{
${ }^{1}$ In 2015 for example, about $92 \%$ of the fuels supplying the US transportation sector were petroleum by-products, according to the United States Energy Information Administration [3].
} 
In order to start to answer these questions, we present in this paper a first theoretical analysis of the consequences of WI on the performance of engine cycles, and more specifically on the density increase of the aspirated fresh mixture.

After a presentation of the different hypotheses considered in the rest, and a short reminder of the good and bad points of WI, its thermodynamic analysis, based on mass and energy balances, will be detailed. An algebraic model specifically developed will be presented, which links the fresh mixture density at the aspiration point with the main parameters of both the intake system and the surroundings (pressure, temperature and so on). Considering some practical applications of this approach, we will show that the interest of such improvement process is dependent on the ambient temperature and humidity ; that the nature of the fuel, the Air-Fuel equivalent ratio $\lambda$ value, and the presence of the fuel itself are almost no influential ; and that in the best situations, so with a very dry air and an intake manifold at relatively high temperature, we cannot expect to increase the amount of aspirated fuel by more than $10 \%$.

The framework presented in this paper will be of a precious help to anyone interested in applying or optimising such improvement strategy on given or future engines.

\subsection{Hypotheses}

This paper is focused on the sole fresh charge cooling effect and on its consequences on the density of the fresh mixture aspirated by the engine. For so, we will consider the followed hypotheses:

H1. The indirect injection, i.e. done in the engine intake manifold and not directly into the engine cylinders, is the only one considered in the present paper.

H2. Neat water is the sole fluid to be injected, although injecting different blends, composed for instance of hydrous ethanol as presented in $[8,9]$, could be modelled with the very same approach.

H3. Water is the sole component to be vaporised in the intake manifold. This hypothesis implies that the liquid fuels potentially consumed are already in a gaseous state when mixed with fresh air, and that we neglect their respective enthalpies of vaporisation, at least in front of the liquid water one.

H4. Water is injected as a liquid downstream of the fuel, as represented in Figure 1, although the opposite situation sometimes occurs, as presented in references [10] or [11] for instance. This hypothesis is justified by the low proportion of fuel within the fresh mixture, that induces an insignificant effect of the presence of the fuel on the whole cooling process.

H5. The whole water injection process is supposed as adiabatic.

H6. The temperature of the injected liquid water is supposed to be the one of the inner intake manifold, at point 1 in Figure 1.

H7. The pressure drop through the water injection process is supposed as negligible and we assume that $p_{1}=p_{2}$ at points 1 and 2 in Figure 1.

H8. All the gases considered in this study are supposed as perfect, i.e. whom behaviours can be described by the ideal gas law, and whom physical properties are supposed to be independent from temperature. 


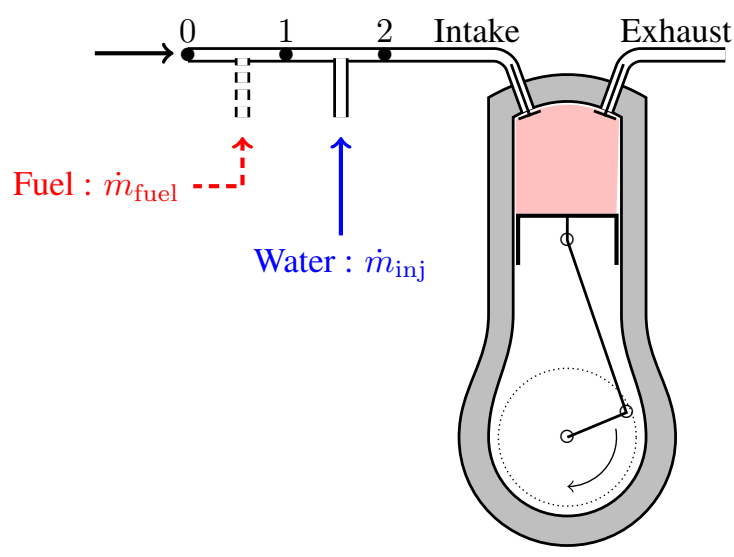

Figure 1: Internal Combustion Engine aspirating fresh air, so a blend of dry air and water vapour due to ambient humidity, from the surroundings at point 0 . Fuel is supposed to be injected between points 0 and 1, so upstream of water which is supposed to be injected between points 1 and 2 . In traditional compression ignited engines, the fuel is injected directly into the cylinder and only after the compression stroke. Humid air is thus the sole component of the fresh mixture mixed with water between points 1 and 2 .

\section{Water injection in internal combustion engines}

\subsection{Effects of water injection}

When injected as liquid into an intake manifold, water evaporates and blends with the engine fresh mixture. We then talk about indirect/port injection of water, inlet manifold water injection or sometimes about intake fumigation. The enthalpy of vaporisation consumed by such phase change process is removed from the enthalpy of the whole intake flow and thus cools down the latter. The resulting temperature drop:

1. increases the fresh mixture density and so the amount of the latter actually aspirated within the engine swept volume. Consequently the mechanical power the engine delivers increases as well. This good point is the one considered in this paper.

2. leads to a lower mechanical work required by the compression stroke, the gas to compress being initially at a lower temperature, and some remaining liquid water being able to be vaporised during the compression in order to "internally" refrigerate the latter [12].

3. decreases the combustion flame temperature, the fresh mixture being at lower temperature at the end of the compression stroke and the heat of combustion being released in a larger amount of gas. The probability of knock phenomena is thus reduced, and the fresh mixture octane number ${ }^{2}$ is increased $[15,16]$. Higher compression ratios can then be reached.

4. increases the amount of gas involved in the expansion stroke and then the mechanical work provided by the latter.

Otherwise, considering the engine polluting emissions, water injection:

1. decreases the amount of nitrogen oxides $\left(\mathrm{NO}_{x}\right)$ finally rejected by the combustion, in decreasing the flame temperature $[8,10,17-20]$. The main source of $\mathrm{NO}_{x}$ is indeed the oxidation process of atmospheric nitrogen contained in the air composing the fresh mixture, due to a too high combustion peak temperature [21]. In doing so, water injection is an adversary of the exhaust gas recirculation (EGR) technology [22].

\footnotetext{
${ }^{2}$ Incidentally, water injection is also known as Anti-Detonant Injection (ADI), see [13, 14].
} 
2. increases the production of unburnt hydrocarbons (UHC), purportedly because of an increase of the quenching layer of combustion, due to the cooling process of the cylinder inner surface, see [23, 24].

3. sometimes decreases or increases the production of carbon monoxide (CO), depending on the specific experimented configuration, as explained in [25].

\subsection{Practical uses of water injection}

The most famous application of such performance improvement strategy is probably the one concerning some supercharged World War II aircraft engines [26], although it has been later applied for the very same reason by Renault on some 1980s F1 supercharged engines [27]. For the sole purpose of $\mathrm{NO}_{x}$ control emissions, water can also be injected directly into the engine cylinder and vaporised, absorbing a fraction of the chemical energy hence released and then decreasing the peak temperature [7, 28, 29]. The latter process has been successfully applied to industrial engines, for example to some marine Diesel engines manufactured by Wärtsilä [30, page 73]. More recently, BMW reintroduced the use of water injection on its M4 GTS model, with an announced will to spread this process on other commercialised vehicles in the future [31].

\section{Thermodynamics of humid fresh mixtures}

When injected as liquid or spray into an engine intake manifold, water, in vaporising, decreases the temperature of the fresh mixture. Incidentally, the very same cooling effect is sometimes used in heating, ventilation and air conditioning (HVAC) systems, in order to humidify and cool down the air flow rate injected into buildings [32]. For such a reason, a specific formalism has been developed in order to treat the humidification process of intake fresh mixtures, similar to the one used in psychrometrics, the field of engineering concerned with humid air related processes.

\subsection{Mass balance of the water injection process}

\subsubsection{Fresh mixture flow rate}

While for HVAC systems, the gas stream to cool down is only composed of dry air and water, for internal combustion engines (ICE) we often have to add the fuel, as for spark ignited or dual fuel compression ignited engines [33]. After fuel injection, so at point 1 or 2 in Figure 1, the whole humid gas mass flow rate under concern can then be expressed as the sum:

$$
\dot{m}_{i}=\dot{m}_{\mathrm{fuel}}+\dot{m}_{\mathrm{air}}+\dot{m}_{w, i}=\dot{m}_{\mathrm{dfm}}+\dot{m}_{w, i}
$$

With $i=\{1,2\}$ and the subscripts "air", " $w "$ and "dfm" meaning dry air, water and dry fresh mixture (so air and fuel), respectively. It is worth noting that the existence of the water flow rate $\dot{m}_{w}$ is due for a part to the water injection process, but also to the surrounding air humidity, corresponding to point 0 in Figure 1. Equation (1) must now be improved by introducing several important and useful dimensionless parameters.

\subsubsection{Air-Fuel Ratio}

The Air-Fuel Ratio, henceforth noted AFR, is defined as the ratio of the combustive dry air mass flow rate consumed by the engine, over the fuel one:

$$
\mathrm{AFR}=\frac{\dot{m}_{\text {air }}}{\dot{m}_{\text {fuel }}} \Rightarrow \dot{m}_{\text {air }}=\dot{m}_{\text {fuel }} \cdot \mathrm{AFR}
$$


From definition (2), we can then express the dry fresh mixture flow rate $\dot{m}_{\mathrm{dfm}}$ of Equation (1) as:

$$
\dot{m}_{\mathrm{dfm}}=\varphi \cdot \dot{m}_{\text {fuel }}+\dot{m}_{\text {air }}=\dot{m}_{\text {fuel }} \cdot(\varphi+\mathrm{AFR})
$$

$\varphi$ is a parameter equal to unity if the fuel is actually mixed with air in the fresh mixture before the intake valve, or equal to zero otherwise:

- Fuel is indeed injected into "traditional" compression ignited (CI) engines directly into the cylinder and only near the end of the compression stroke [21]. In Equation (3), it means $\varphi=0$.

- On the contrary, in spark ignited (SI) or dual fuel CI engines, fuel is mixed with air during the intake process and we have $\varphi=1$ in Equation (3).

The AFR value depends on the fuel chemical composition and of the effective Air-Fuel equivalence Ratio, often noted $\lambda$ and defined as:

$$
\lambda=\frac{\mathrm{AFR}}{\mathrm{AFR}_{\mathrm{st}}}
$$

with subscript "st" that means stoichiometric. Thus, $\lambda=1$ for a stoichiometric combustion, while $\lambda>1$ for a lean combustion, i.e. with excess air, and $\lambda<1$ for a rich combustion [21].

\subsubsection{Specific water content}

The parameter sometimes called specific humidity, moisture content, humidity ratio or mixing ratio, noted $\omega$, is traditionally defined, for a given amount of humid air, as the ratio of the water vapour mass, over the dry air one [32]. For ventilating systems, this way to quantify the humidity of air is usually preferred to a more common mass fraction. Indeed, during an humidification or drying process, whereas the amount of water vapour actually contained in a given amount of humid gas may vary, the corresponding amount of the sole dry gas remains the same. Using $\omega$ instead of a mass fraction helps then to simplify the resulting calculations. The dry gas under concern in this study being the dry fresh mixture of Equation (3), we have at point $i$ :

$$
\omega_{i}=\frac{\dot{m}_{w, i}}{\dot{m}_{\mathrm{dfm}}}=\frac{\dot{m}_{w, i}}{\dot{m}_{\mathrm{fuel}} \cdot(\varphi+\mathrm{AFR})}
$$

A further difference with usual HVAC systems is the potential presence of liquid water mixed, as fog for instance, with the fresh mixture stream. As we shall explain in the rest, it is possible to inject more water than the maximal amount which is possible to evaporate. As long as no "cold spot" exists within the intake system, which can imply some premature liquefaction phenomena, the water droplets can be transported until the inside of the cylinder. The latter process can be beneficial for the engine compression stroke for instance, because of the cooling effect of water droplets evaporation inside the swept volume, as it occurs with direct injection of water presented in references $[13,29,34-36]$. As a consequence and for clarity purposes, $\omega$ will be henceforth called specific water content.

\subsubsection{Water-Fuel Ratio}

The Water-Fuel Ratio, noted WFR in the rest, is the fundamental parameter of water injection systems. It is defined as the ratio of the injected liquid water mass flow rate $\dot{m}_{\text {inj }}$, over the fuel one $\dot{m}_{\text {fuel }}$ (see Figure 1):

$$
\mathrm{WFR}=\frac{\dot{m}_{\text {inj }}}{\dot{m}_{\text {fuel }}} \Rightarrow \dot{m}_{\text {inj }}=\dot{m}_{\text {fuel }} \cdot \text { WFR }
$$

Depending on the concerned application, the Water-Fuel Ratio can be typically such as $0.2 \leq$ $\mathrm{WFR} \leq 1.5$, as presented for instance in references [6, 24, 28, 29, 37]. Anyway, its value has 


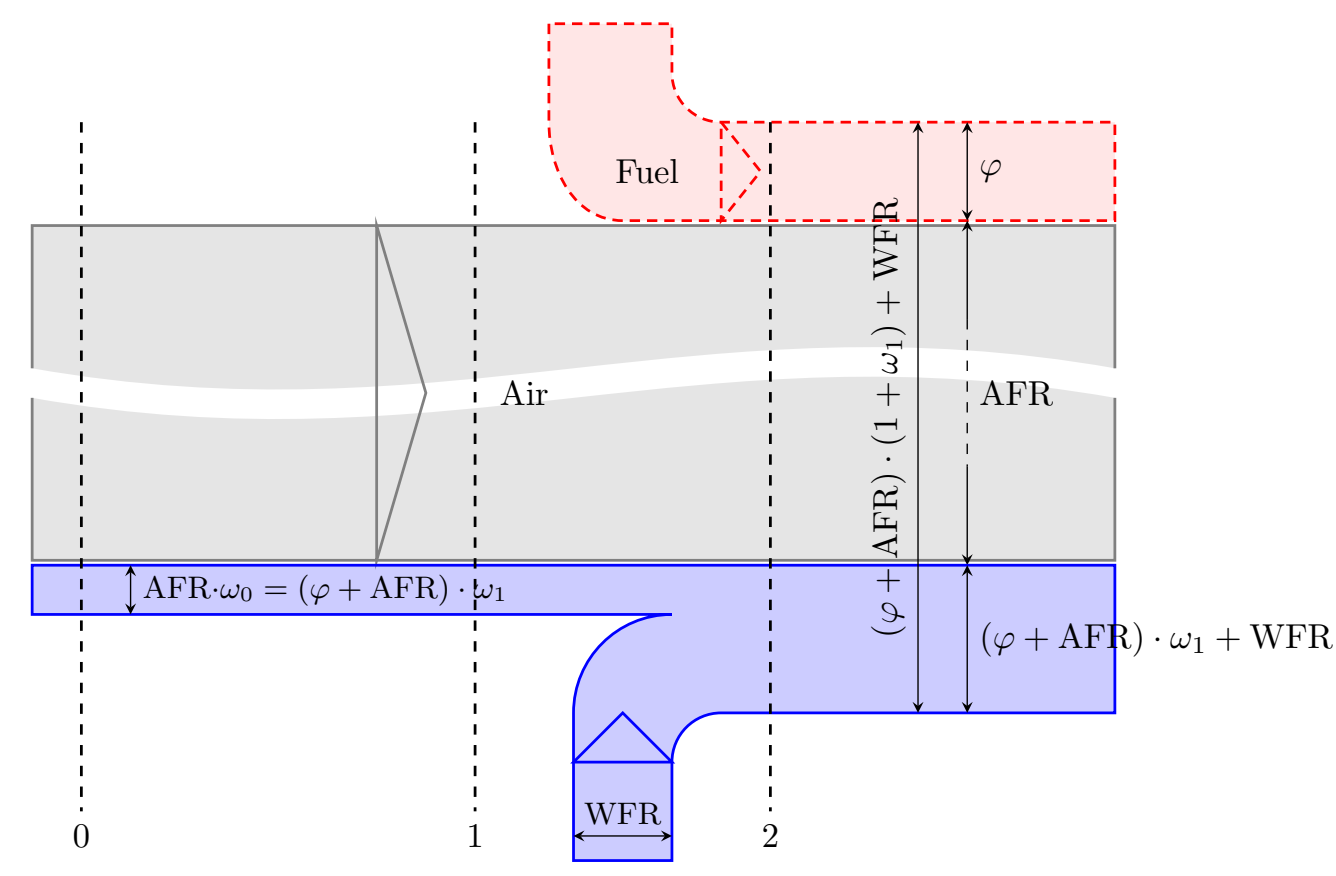

Figure 2: Simplified representation of the fresh mixture composition, with points 0 to 2 corresponding to the ones of Figure 1.

been so far chosen from experimental approaches only, usually in order to optimise the power finally produced by the engine. We will use it in the rest for the same purpose, but in a quite different way.

Using AFR and $\omega$, respectively defined by Equations (2) and (5), the fresh mixture mass flow rate at point $i$, previously expressed by Equation (1), can now be written as the product:

$$
\dot{m}_{i}=\dot{m}_{\text {fuel }} \cdot(\varphi+\mathrm{AFR}) \cdot\left(1+\omega_{i}\right)
$$

The difference between the mass flow rate of Equation (7), when considered at point 2 and 1, being equal to the liquid water injected one $\dot{m}_{\text {inj }}$ defined by (6) (see in Figure 1), we obtain a new expression of the Water-Fuel Ratio:

$$
\mathrm{WFR}=(\varphi+\mathrm{AFR}) \cdot\left(\omega_{2}-\omega_{1}\right)
$$

With the specific water content at point 1 calculated from the surrounding one at point 0 according to:

$$
\omega_{1}=\frac{\mathrm{AFR}}{\varphi+\mathrm{AFR}} \cdot \omega_{0}
$$

Fuel being possibly mixed with fresh air between point 0 and 1 in Figure 1, the dry gas flow rate thanks to whom specific water content $\omega$ is defined has changed in the meanwhile, so the value $\varphi=1$ in Equation (9). If not, we have $\omega_{1}=\omega_{0}$ for $\varphi=0$, as represented for instance in Figure 2 . Practically, most hydrocarbon fuels have and AFR $\simeq 15$ and so $\omega_{1} / \omega_{0}=15 / 16 \simeq 0.94$.

\subsubsection{Gaseous and liquid phases of water}

The cooling effect of the fresh mixture being created by the vaporisation of the injected liquid water, at first glance, the larger the amount of the latter, the larger the resulting mixture temperature drop. The amount of liquid water which can be actually vaporised is yet limited by 
the equilibrium state between liquid water and vapour, often clumsily called "saturated" state of air $^{3}$.

Indeed, the water vapour concentration within the fresh mixture will never exceed the one represented by the equilibrium vapour pressure, noted $p_{\text {eq }}$ in the rest, so the partial pressure of water vapour when in equilibrium with its liquid phase. Practically, $p_{\text {eq }}$ depends on relative temperature $\theta$ only, and can be calculated thanks to experimental correlations as for example the Hyland and Wexler [39] one. The molar fraction of water vapour into the fresh mixture being equal to its partial pressure, according to the Dalton's law, we always have:

$$
\frac{n_{\mathrm{vap}}}{n} \leq \frac{p_{\mathrm{eq}}(\theta)}{p}
$$

with $n$ the molar amount of matter, in mol, $p$ the "total" pressure of the fresh mixture in the intake manifold and the subscript "vap" meaning water vapour. If combined with the definition of Equation (5) of the specific vapour content $\omega$, Equation (10) leads to a maximum value of the same parameter, considered for example at point 2 , such as:

$$
\omega_{\text {vap }, \text { eq }}\left(p_{2}, \theta_{2}\right)=\alpha_{w} \cdot \underbrace{\frac{\varphi+\alpha_{\text {fuel }} \cdot \operatorname{AFR}}{\alpha_{\text {fuel }} \cdot(\varphi+\mathrm{AFR})}}_{\text {(1) }} \cdot \frac{p_{\text {eq }}\left(\theta_{2}\right)}{p_{2}-p_{\text {eq }}\left(\theta_{2}\right)}
$$

With $p_{2}$ and $\theta_{2}$ the fresh mixture pressure and temperature at point 2, respectively, and the constants $\alpha$ 's defined as:

$$
\alpha_{w}=\frac{M_{w}}{M_{\text {air }}} \simeq 0.62198 \quad \alpha_{\text {fuel }}=\frac{M_{\text {fuel }}}{M_{\text {air }}}
$$

$M$ is the molar mass of each component. It is important to note that $\theta_{2}$ is here the fresh mixture temperature at the intake valve point, so after the cooling effect due to water injection. Thus, it will be the result of a further calculation explained in the rest. Once again, without any fuel mixed with dry air, so with $\varphi=0$, fraction $(1)=1$ and Equation (11) is the one usually used for air conditioning systems [32].

\subsubsection{Equilibrium Water-Fuel Ratio}

To the maximal amount of water vapour contained in the fresh mixture after the water injection process, represented by $\omega_{\text {vap,eq }}$ of Equation (11), corresponds a specific value of the Water-Fuel Ratio noted $W_{F R}$. The latter is by definition the largest value of the WFR that ensure a complete vaporisation of the injected liquid mass flow rate $\dot{m}_{\mathrm{inj}}$. On the contrary, if WFR > WFR $_{\text {eq }}$, a fraction of $\dot{m}_{\text {inj }}$ cannot be vaporised and is blend as liquid with the fresh mixture. According to (8) and (11), we have then:

$$
\mathrm{WFR}_{\mathrm{eq}}=(\varphi+\mathrm{AFR}) \cdot\left(\omega_{\mathrm{vap}, \mathrm{eq}}-\omega_{1}\right)
$$

In the rest of this paper, we will suppose that a liquid fraction exists at the intake point only if WFR $>\mathrm{WFR}_{\mathrm{eq}}$. Such hypothesis means that any amount of liquid which can be evaporated, actually is. Furthermore, as previously mentioned, the intake valve temperature $\theta_{2}$, and so the equilibrium Water-Fuel Ratio $\mathrm{WFR}_{\mathrm{eq}}$, are the results of another calculation presented in the rest. In practical applications, it is important to keep in mind that pressure $p_{2}$, and thus temperature $\theta_{2}$, can widely vary regarding to the possible use of ancillary systems not drawn on Figure 1, as e.g. a supercharger, a turbocharger, an intercooler, and so on.

\footnotetext{
${ }^{3}$ As clearly reminded in reference [38, chapter 5] for instance, this so-called "saturation" state of air has actually nothing to do with air itself, or with any other dry gas humidified by water. The use of the word "saturation" in such context is then clearly misleading regarding to the actual physical processes involved. This is why we will avoid it in the rest.
} 


\subsubsection{Intake valve fresh mixture composition}

From the combination of Equation (7) considered at point 2 and of Equations (8) and (9), it is possible to express the whole fresh mixture mass flow rate at the same point as:

$$
\dot{m}_{2}=\dot{m}_{\text {fuel }} \cdot\left(\varphi+\mathrm{AFR} \cdot\left(1+\omega_{0}\right)+\mathrm{WFR}\right)
$$

And the respective fractions of fuel, air and water can be expressed at the same location in dividing the corresponding mass flow rates by the one of Equation (14), so for fuel:

$$
x_{\text {fuel }, 2}=\frac{\dot{m}_{\text {fuel }}}{\dot{m}_{2}}=\frac{\varphi}{\varphi+\mathrm{AFR} \cdot\left(1+\omega_{0}\right)+\mathrm{WFR}}
$$

For air:

$$
x_{\mathrm{air}, 2}=\frac{\dot{m}_{\mathrm{air}}}{\dot{m}_{2}}=\frac{\mathrm{AFR}}{\varphi+\mathrm{AFR} \cdot\left(1+\omega_{0}\right)+\mathrm{WFR}}
$$

And for water in both phases:

$$
x_{w, 2}=\frac{\dot{m}_{w, 2}}{\dot{m}_{2}}=\frac{\mathrm{AFR} \cdot \omega_{0}+\mathrm{WFR}}{\varphi+\mathrm{AFR} \cdot\left(1+\omega_{0}\right)+\mathrm{WFR}}
$$

It is easy to check that the sum of Equations (15), (16) and (17) is indeed always equal to unity. The distinction between the water vapour fraction and the liquid water one is made thanks to the equilibrium value of the Water-Fuel Ratio, as defined by Equation (13). Hence, while the water vapour fraction is the one of Equation (17) if WFR $\leq \mathrm{WFR}_{\text {eq }}$, we have in the opposite situation (when WFR $>\mathrm{WFR}_{\text {eq }}$ ):

$$
x_{\mathrm{vap}, 2}=\frac{\dot{m}_{\mathrm{vap}, 2}}{\dot{m}_{2}}=\frac{\mathrm{AFR} \cdot \omega_{0}+\mathrm{WFR}_{\mathrm{eq}}}{\varphi+\mathrm{AFR} \cdot\left(1+\omega_{0}\right)+\mathrm{WFR}}
$$

and:

$$
x_{\mathrm{liq}, 2}=\frac{\dot{m}_{\mathrm{liq}, 2}}{\dot{m}_{2}}=\frac{\mathrm{WFR}-\mathrm{WFR}_{\mathrm{eq}}}{\varphi+\mathrm{AFR} \cdot\left(1+\omega_{0}\right)+\mathrm{WFR}}
$$

Thus, we always have $x_{w, 2}=x_{\mathrm{vap}, 2}+x_{\mathrm{liq}, 2}$.

\subsection{Energy balance of the cooling process}

As previously explained, the liquid water injection process induces the fresh mixture cooling thanks to an exchange of the whole gaseous mixture enthalpy for the liquid water enthalpy of vaporisation. It is worth noting that the very same phenomenon also exists for other injected liquids, as e.g. the liquid fuels commonly consumed by such engines, but with a weaker cooling effect due to a comparatively greater value of the water enthalpy of vaporisation $(\geq 6 \times$ the octane and cetane ones and $\geq 4 \times$ the ethanol's one, see in Table 1 page 12), so the hypothesis H3 of page 3.

Anyhow, the energy balance of such an open process can be established in considering the enthalpy rate of each flow under concern. The one of the humid fresh mixture can be expressed at point $i$ using AFR and $\omega$ of Equations (2) and (5), as:

$$
\begin{aligned}
(\dot{m} \cdot h)_{i} & =\varphi \cdot \dot{m}_{\text {fuel }} \cdot h_{\text {fuel }, i}+\dot{m}_{\text {air }} \cdot h_{\text {air }, i}+\dot{m}_{w, i} \cdot h_{w, i} \\
& =\dot{m}_{\text {fuel }} \cdot\left(\varphi \cdot h_{\text {fuel }, i}+\operatorname{AFR} \cdot h_{\text {air }, i}+(\varphi+\operatorname{AFR}) \cdot \omega_{i} \cdot h_{w, i}\right)
\end{aligned}
$$

The $h$ 's are the usual specific enthalpies of fuel, air and water, respectively, both expressed in $\mathrm{kJ} / \mathrm{kg}$, and depending on the local temperature (so the subscripts " $i$ "). As for water content of Equation (5) for example, it is common when studying heat, ventilation and air conditioning (HVAC) systems, to divide all extensive parameters by the constant flow rate, here the one of 
air and fuel, so $\dot{m}_{\mathrm{dfm}}$ of Equation (3). In doing so to the enthalpy rate of Equation (20), we obtain a first expression of the specific enthalpy of the humid fresh mixture at point $i$ :

$$
\underline{h}_{i}=\frac{(\dot{m} \cdot h)_{i}}{\dot{m}_{\mathrm{dfm}}}=\frac{\varphi \cdot h_{\mathrm{fuel}, i}+\mathrm{AFR} \cdot h_{\mathrm{air}, i}}{\varphi+\mathrm{AFR}}+\omega_{i} \cdot h_{w, i}=\underline{h}_{\mathrm{dfm}, i}+\omega_{i} \cdot h_{w, i}
$$

Once again, this expression is the one used for HVAC applications, so with dry air only, as long as no fuel is involved and then as $\varphi=0$.

Considering now the energy balance of the water injection system of Figure 1, supposed as adiabatic according to hypothesis H5, we have, in using the specific enthalpy of Equation (21):

$$
\dot{m}_{\mathrm{dfm}} \cdot\left(\underline{h}_{\mathrm{dfm}, 1}+\omega_{1} \cdot h_{w, 1}\right)+\dot{m}_{\mathrm{inj}} \cdot h_{\mathrm{inj}}=\dot{m}_{\mathrm{dfm}} \cdot\left(\underline{h}_{\mathrm{dfm}, 2}+\omega_{2} \cdot h_{w, 2}\right)
$$

According to previous assumptions, the water blended with fresh mixture can be composed at intake point 2 of vapour only, or on liquid and vapour, depending on the value of the actual Water-Fuel Ratio. As long as WFR $\leq \mathrm{WFR}_{\text {eq }}$, the concerned water is thus only in a vapour phase at intake valve point 2 , whereas liquid and vapour can be both presents otherwise.

\subsection{Complete vaporisation}

In the first situation, so if $\mathrm{WFR} \leq \mathrm{WFR}_{\mathrm{eq}}$, water is only present within the fresh mixture as a vapour, and the specific enthalpy of water is the one of its vapour phase only. At intake valve point 2, we have:

$$
\omega_{2} \cdot h_{w, 2}=\omega_{2} \cdot h_{\mathrm{vap}, 2}
$$

$h_{\text {vap }}$ is here the specific enthalpy of water vapour alone. We also have, according to Equations (6) and (8), the specific enthalpy of the injected liquid water:

$$
\dot{m}_{\text {inj }} \cdot h_{\text {inj }}=\dot{m}_{\text {fuel }} \cdot \mathrm{WFR} \cdot\left(-\ell_{w, 1}\right)
$$

$\ell_{w, 1}$ is the specific enthalpy of vaporisation of water at temperature $\theta_{1}$ - according to hypothesis $\mathrm{H} 6$ - which corresponds to the amount of heat required to vaporise, at constant pressure, one unit of mass of liquid water taken at this temperature. Equation (24) also includes a minus sign "_" because of the fundamental endothermic nature of vaporisation processes.

When applied to this water injection process with a complete vaporisation, the energy balance of Equation (22), combined with Equations (23) and (24) leads to the follow equality:

$$
\underline{h}_{\mathrm{dfm}, 1}+\omega_{1} \cdot\left(h_{\mathrm{vap}, 1}+\ell_{w, 1}\right)=\underline{h}_{\mathrm{dfm}, 2}+\omega_{2} \cdot\left(h_{\mathrm{vap}, 2}+\ell_{w, 2}\right)
$$

and so to an equality between two specific enthalpies of humid fresh mixture:

$$
\underline{h}_{1}=\underline{h}_{2} \Leftrightarrow \underline{h}_{i}=\underline{h}_{\mathrm{dfm}, i}+\omega_{i} \cdot\left(h_{\mathrm{vap}, i}+\ell_{w, i}\right)
$$

It is quite usual now: definition (26) is exactly the one used in ventilation systems if the dry fresh mixture is composed by the sole dry air [32] and so if $\underline{h}_{\mathrm{dfm}}=h_{\text {air }}$ and $\varphi=0$. Moreover, as it is usual to in psychrometrics, we will neglect the variation of the enthalpy of vaporisation between temperatures at point 1 and at point 2 . The variation of $\ell_{w}$ being for instance lower than $8 \%$ between $0^{\circ} \mathrm{C}$ and $80^{\circ} \mathrm{C}$.

\subsection{Incomplete vaporisation}

If the injected water flow rate $\dot{m}_{\text {inj }}$ is too large to be completely vaporised, i.e. if $\mathrm{WFR}>\mathrm{WFR}_{\text {eq }}$, liquid and vapour phases are both present after the water injection point, so at the intake valve point 2 in Figure 1. The corresponding enthalpy of water at the very same point is then:

$$
\omega_{2} \cdot h_{w, 2}=\underbrace{\omega_{\mathrm{vap}, \mathrm{eq}, 2} \cdot h_{\mathrm{vap}, 2}}_{\text {(1) }}+\underbrace{\left(\omega_{2}-\omega_{\mathrm{vap}, \mathrm{eq}, 2}\right) \cdot h_{\mathrm{liq}, 2}}_{\text {(2) }}
$$


(1) corresponds to the fraction of the liquid water injected which is completely vaporised and (2) is the one remaining as liquid. The enthalpy rate of the liquid water injected may also vary regarding to WFR and we have, according to (3), (8) and (13):

$$
\dot{m}_{\mathrm{inj}} \cdot h_{\mathrm{inj}}=\underbrace{\dot{m}_{\text {fuel }} \cdot \mathrm{WFR}_{\mathrm{eq}} \cdot\left(-\ell_{w, 1}\right)}_{(1)}+\underbrace{\dot{m}_{\text {fuel }} \cdot\left(\mathrm{WFR}-\mathrm{WFR}_{\mathrm{eq}}\right) \cdot h_{\mathrm{liq}, 1}}_{\text {(2) }}
$$

With (1) and (2) which have the same physical meaning as in Equation (27). When applied to a water injection process with WFR $>\mathrm{WFR}_{\mathrm{eq}}$, the same energy balance, based on the combination of Equations (22), (27) and (28), leads to:

$$
\underline{h}_{1}-\underline{h}_{2}=\left(\omega_{2}-\omega_{\mathrm{vap}, \mathrm{eq}}\right) \cdot\left(h_{\mathrm{liq}, 2}-h_{\mathrm{liq}, 1}\right)
$$

The difference between the humid fresh mixture specific enthalpy when considered at point 1 and 2 is now equal to the enthalpy absorbed by the non evaporated water. Hence, to this non vaporised water corresponds a further specific enthalpy, which increases the one of the whole stream cooled down by the vaporisation effect. We shall see in the rest that such phenomenon leads to a smaller temperature drop of the fresh mixture.

It is important to note that Equation (29) does not mean that the enthalpy rate of the whole process is not conserved: the injection process is still supposed as adiabatic (hypothesis $\mathrm{H} 5$ ). It means that the specific enthalpy of the humid fresh mixture, as defined by Equation (26) in order to be conserved through a complete evaporation process, is not conserved anymore when the injected flow rate cannot be entirely vaporised.

Using the conventional formalism of psychrometrics, we can express each specific enthalpy $h$ thanks to a temperature difference - all gases are supposed to be perfect, according to hypothesis $\mathrm{H} 8$ - such as:

$$
\Delta h=h-h_{\mathrm{ref}}=\int_{T_{\mathrm{ref}}}^{T} c_{p}(\vartheta) \cdot d \vartheta \simeq \bar{c}_{p} \cdot\left(T-T_{\mathrm{ref}}\right)
$$

with $\bar{c}_{p}$ the average specific heat at constant pressure within the considered temperature range $T_{\text {ref }} \leq \vartheta \leq T$, and $h_{\text {ref }}$ the reference enthalpy value taken at reference temperature $T_{\text {ref }}$. Conventionally, in psychrometrics, we consider that $h_{\text {ref }}=0 \mathrm{~J} / \mathrm{kg}$ at $T_{\text {ref }}=0^{\circ} \mathrm{C}$ and so for each component we have:

$$
h=\bar{c}_{p} \cdot \theta
$$

with $\theta$ the relative temperature. Combining Equations (26) and (31) with a constant water enthalpy of vaporisation, we obtain a new expression of the fresh mixture specific enthalpy at point $i$ :

$$
\underline{h}_{i}=\bar{c}_{p, \mathrm{dfm}} \cdot \theta_{i}+\omega_{i} \cdot\left(\bar{c}_{p, \mathrm{vap}} \cdot \theta_{i}+\ell_{w}\right)=\left(\bar{c}_{p, \mathrm{dfm}}+\omega_{i} \cdot \bar{c}_{p, \mathrm{vap}}\right) \cdot \theta_{i}+\omega_{i} \cdot \ell_{w}
$$

With the specific heat at constant pressure of the dry fresh mixture:

$$
\bar{c}_{p, \mathrm{dfm}}=\frac{\varphi \cdot \bar{c}_{p, \mathrm{fuel}}+\mathrm{AFR} \cdot \bar{c}_{p, \text { air }}}{\varphi+\mathrm{AFR}}
$$

In psychrometrics, the values of $\ell_{w}=2501 \mathrm{~kJ} / \mathrm{kg}$ and $\bar{c}_{p, \text { liq }} \simeq 4.18 \mathrm{~kJ} /(\mathrm{kg} \cdot \mathrm{K})$ are conventionally considered at a reference temperature of $0^{\circ} \mathrm{C}$, as reminded in [32]. The other physical properties considered in this paper are presented in Table 1. We will use the same convention in the rest, although the temperature ranges considered here are slightly more away from this reference temperature of $0^{\circ} \mathrm{C}$ than the typical ones for air conditioning systems. 


\subsection{Cooling effect and wet-bulb temperature}

If we consider the water injection with a complete vaporisation, so with $\mathrm{WFR} \leq \mathrm{WFR}_{\text {eq }}$, we have, using Equations (26) and (32), an intake temperature drop $\theta_{2}-\theta_{1}$ such as:

$$
\theta_{2}-\theta_{1}=-\frac{\bar{c}_{p, \mathrm{vap}} \cdot \theta_{1}+\ell_{w}}{\bar{c}_{p, \mathrm{dfm}}+\omega_{2} \cdot \bar{c}_{p, \mathrm{vap}}} \cdot\left(\omega_{2}-\omega_{1}\right)
$$

We can then express the specific water content $\omega$ as functions of the Water-Fuel Ratio, according to Equation (8), in order to obtain:

$$
\theta_{2}-\theta_{1}=-\frac{\left(\bar{c}_{p, \mathrm{vap}} \cdot \theta_{1}+\ell_{w}\right) \cdot \mathrm{WFR}}{(\varphi+\mathrm{AFR}) \cdot\left(\bar{c}_{p, \mathrm{dfm}}+\omega_{1} \cdot \bar{c}_{p, \mathrm{vap}}\right)+\bar{c}_{p, \mathrm{vap}} \cdot \mathrm{WFR}}
$$

However, because we usually have $\ell_{w} \gg \bar{c}_{p, \text { vap }} \cdot \theta_{1}$ and $(\varphi+\mathrm{AFR}) \cdot\left(\bar{c}_{p, \mathrm{dfm}}+\omega_{1} \cdot \bar{c}_{p \text {,vap }}\right) \gg$ $\bar{c}_{p \text {,vap }} \cdot$ WFR, the temperature difference $\theta_{2}-\theta_{1}$ corresponding to the researched cooling effect can be expressed in an approximative but linear form regarding to Water-Fuel Ratio, as:

$$
\theta_{2}-\theta_{1} \simeq-\frac{\ell_{w} \cdot \mathrm{WFR}}{(\varphi+\mathrm{AFR}) \cdot\left(\bar{c}_{p, \mathrm{dfm}}+\omega_{1} \cdot \bar{c}_{p, \mathrm{vap}}\right)}
$$

Hence, as long as the equilibrium state between liquid water and vapour is not reached, the greater the WFR, the greater the cooling effect of the fresh mixture.

In the pyschrometric or Carrier diagram $(\theta, \omega)$ in Figure 3 , when the vaporisation is complete and so when $\underline{h}_{2}=\underline{h}_{1}$, the point $\left(\theta_{2}, \omega_{2}\right)$ corresponding to intake valve point 2 is moving upward along the straight line representing the constant value of specific enthalpy $\underline{h}_{2}=\underline{h}_{1}$. Thus, the maximum possible temperature drop is attained when the difference of specific water content is maximum as well, so when the line of $\underline{h}_{2}$ reach the curve corresponding to the equilibrium vapour pressure, with $\omega_{2}=\omega_{\text {vap,eq. }}$. In this case, the lowest intake temperature reached is by definition the wet-bulb temperature, noted $\theta_{\mathrm{wb}}$ [32]. The value of $\theta_{\mathrm{wb}}$ can be practically obtained in solving Equation (37), obtained from $\underline{h}_{2}=\underline{h}_{1}$, and from Equations (11) and (32):

$$
\bar{c}_{p, \mathrm{dfm}} \cdot \theta_{\mathrm{wb}}+\omega_{\mathrm{vap}, \mathrm{eq}}\left(p_{2}, \theta_{\mathrm{wb}}\right) \cdot\left(\bar{c}_{p, \mathrm{vap}} \cdot \theta_{\mathrm{wb}}+\ell_{w}\right)=\underline{h}_{1}
$$

Whereas for dry air only, some correlations have been developed to compute directly $\theta_{\mathrm{wb}}$ for $\theta_{1}$ and $\omega_{1}$, Equation (37) is here practically solved thanks to a specific numerical Newton's algorithm, because of the potential presence of fuel in the fresh mixture with $\bar{c}_{p, \mathrm{dfm}} \neq \bar{c}_{p, \text { air }}$; and because of pressure $p_{2}$ which can be clearly different from the atmospheric one.

In this way, the wet-bulb temperature is the lowest one of the intake valve point 2 , because it corresponds to the maximum amount of vaporised liquid water. Thus, this temperature is

Table 1: Main physical properties of the chemical components considered as gases in this study. Datas extract from [32] and considered at $T=273 \mathrm{~K}$ for dry air and water vapour ; and from the National Institute of Standards and Technology [40] at $T=298 \mathrm{~K}$ for the other components.

\begin{tabular}{lcccc}
\hline Component & $\begin{array}{c}M \\
{[\mathrm{~g} / \mathrm{mol}]}\end{array}$ & $\begin{array}{c}r \\
{[\mathrm{~J} /(\mathrm{kg} \cdot \mathrm{K})]}\end{array}$ & $\begin{array}{c}c_{p} \\
{[\mathrm{~J} /(\mathrm{kg} \cdot \mathrm{K})]}\end{array}$ & $\begin{array}{c}\ell \\
{[\mathrm{kJ} / \mathrm{kg}]}\end{array}$ \\
\hline Dry air & 28.9645 & 287.055 & 1006 & - \\
Steam & 18.0153 & 461.520 & 1805 & 2501 \\
Ethanol & 46.0684 & 180.480 & 1415 & 547.89 \\
Octane & 114.232 & 72.7853 & 1644 & 363.25 \\
Cetane & 226.448 & 36.7168 & 2210 & 359.02 \\
\hline
\end{tabular}




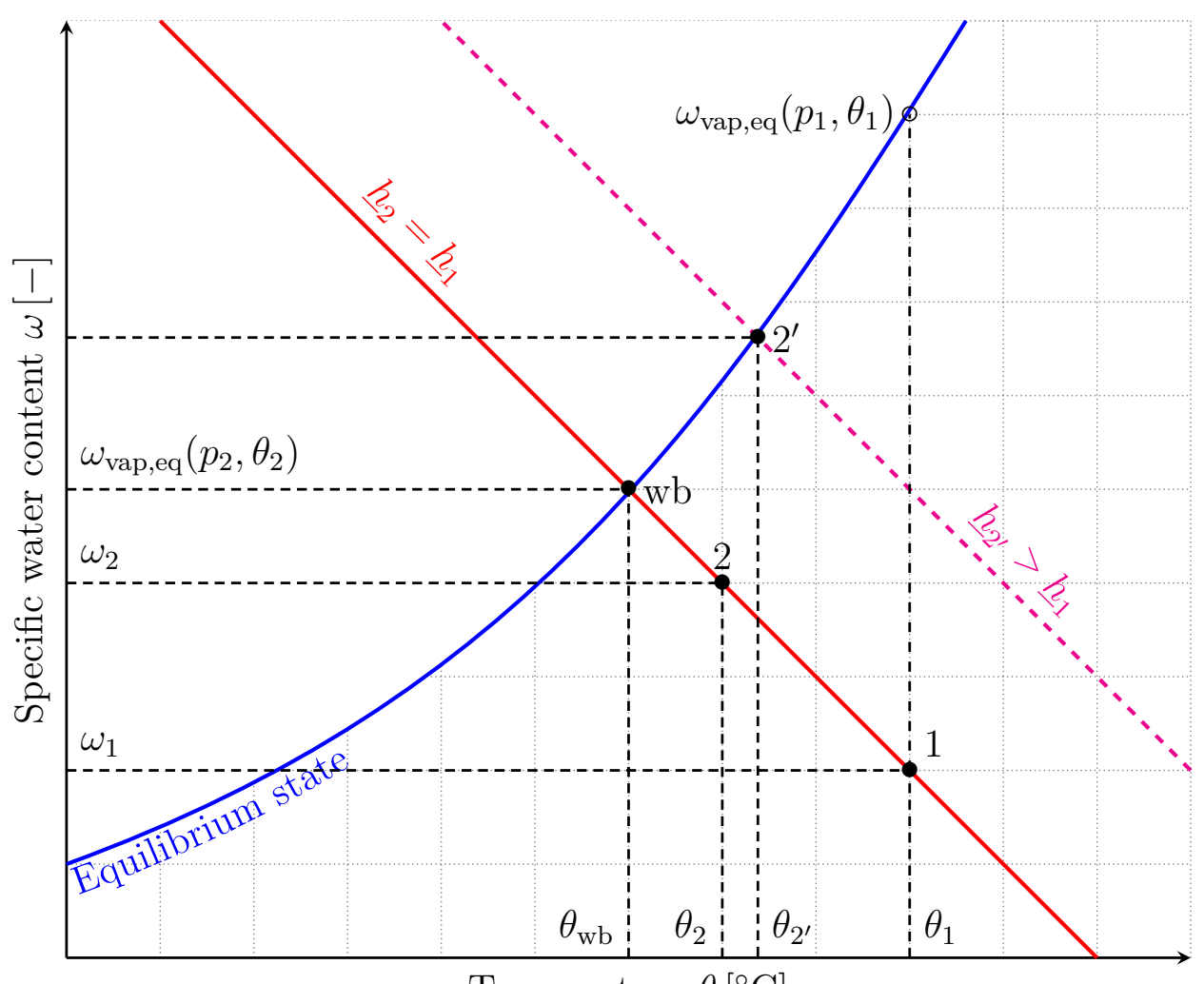

Temperature $\theta\left[{ }^{\circ} \mathrm{C}\right]$

Figure 3: Psychrometric or Carrier diagram $(\theta, \omega)$ commonly used for air conditioning applications. From the point 1 corresponding to the fresh mixture before the water injection process, the specific water content $\omega_{1}$ increases until $\omega_{2}$ and decreases the temperature from $\theta_{1}$ to $\theta_{2}$. For a completely vaporised water injection, any attainable point 2 is on the straight line representing $\underline{h}_{2}=\underline{h}_{1}$. The greatest cooling effect is thus obtained for $\omega_{2}=\omega_{\text {vap,eq }}$. The corresponding temperature is by definition the wet-bulb one noted $\theta_{\mathrm{wb}}$. For incomplete vaporised water, once the wet-bulb temperature is reached, the intake temperature will increase until $\theta_{2^{\prime}}$ because of the remaining liquid water specific enthalpy.

actually the one involved in the definition of the equilibrium Water-Fuel Ratio $W_{F R}$ defined in Equation (13), and we have instead:

$$
\mathrm{WFR}_{\mathrm{eq}}=(\varphi+\mathrm{AFR}) \cdot\left(\omega_{\mathrm{vap}, \mathrm{eq}}\left(p_{2}, \theta_{\mathrm{wb}}\right)-\omega_{1}\right)
$$

The wet-bulb temperature will be of a great importance in the rest because it will be used to calculate the value of the equilibrium Water-Fuel Ratio $\mathrm{WFR}_{\mathrm{eq}}$ according to (38), and then to demarcate the situations corresponding to water injection processes with complete vaporisations, so with $\mathrm{WFR} \leq \mathrm{WFR}_{\text {eq }}$ from the incompletely vaporised ones corresponding to $\mathrm{WFR}>\mathrm{WFR}_{\text {eq }}$.

According to energy balance of Equation (29), the specific enthalpy $\underline{h}$ of the fresh mixture is not conserved anymore when the injected water is not completely vaporised. On the contrary, we have, using Equation (31) in the expressions of the liquid water specific enthalpy, the difference:

$$
\underline{h}_{1}-\underline{h}_{2}=\left(\omega_{2}-\omega_{\mathrm{vap}, \mathrm{eq}}\right) \cdot \bar{c}_{p, \mathrm{liq}} \cdot\left(\theta_{2}-\theta_{1}\right) \leq 0
$$

Because $\theta_{1} \geq \theta_{2}$ and $\omega_{2} \geq \omega_{\text {vap,eq }}$, we have $\underline{h}_{1} \leq \underline{h}_{2}$. When combined with Equation (32), Equation (39) leads to another expression of the temperature difference:

$$
\theta_{2}-\theta_{1}=-\frac{\bar{c}_{p, \text { vap }} \cdot \theta_{1}+\ell_{w}}{\bar{c}_{p, \mathrm{dfm}}+\left(\omega_{2}-\omega_{\mathrm{vap}, \mathrm{eq}}\right) \cdot \bar{c}_{p, \text { liq }}+\omega_{\mathrm{vap}, \mathrm{eq}} \cdot \bar{c}_{p, \text { vap }}} \cdot\left(\omega_{\mathrm{vap}, \mathrm{eq}}-\omega_{1}\right)
$$


The difference of Equation (39) is represented by the line noted $\underline{h}_{2^{\prime}}>\underline{h}_{1}$ in Figure 3. It is then clearly visible on the same diagram that injecting more water than the amount possibly vaporised, so with WFR $>\mathrm{WFR}_{\text {eq }}$, leads to a smaller temperature drop such as $\left|\theta_{2^{\prime}}-\theta_{1}\right|<$ $\left|\theta_{\mathrm{wb}}-\theta_{1}\right|$.

It is worth noting that Equation (40) must be understood in a slightly different way than previous Equation (34). Indeed, as long as WFR and then $\omega_{2}$ increase, so the difference $\omega_{2}-$ $\omega_{\text {vap,eq }}$, that leads to a decrease of the temperature drop $\left|\theta_{2}-\theta_{1}\right|$. At the same time yet, the intake temperature $\theta_{2}$ thanks to whom the equilibrium specific water content $\omega_{\text {vap,eq }}$ is calculated varies as well, inducing a more complicated evolution of the temperature difference $\theta_{2}-\theta_{1}=f(\mathrm{WFR})$. Anyway, the maximum drop always corresponds to a Water-Fuel Ratio equal to the equilibrium one:

$$
\mathrm{WFR}_{\mathrm{eq}}=\arg \max _{\mathrm{WFR}}\left(\left|\theta_{2}-\theta_{1}\right|\right)
$$

Practically though, the intake temperature $\theta_{2}$ can not be calculated "directly" in solving Equation (40), but rather by solving Equation (42), similar to Equation (37) used to compute the wet-bulb temperature:

$$
\left(\bar{c}_{p, \mathrm{dfm}}+\omega_{2} \cdot \bar{c}_{p, \text { liq }}\right) \cdot \theta_{2}+\omega_{\text {vap }, \mathrm{eq}}\left(p_{2}, \theta_{2}\right) \cdot\left(\left(\bar{c}_{p, \text { vap }}-\bar{c}_{p, \text { liq }}\right) \cdot \theta_{2}+\bar{c}_{p, \text { liq }} \cdot \theta_{1}+\ell_{w}\right)=\underline{h}_{1}-\omega_{2} \cdot \bar{c}_{p, \text { liq }} \cdot \theta_{1}
$$

The intake valve temperature $\theta_{2}$ and all the other resulting parameters can now be calculated for any specific configuration of the water injection process.

\subsection{Intake valve temperature}

Let us suppose as known the "primary" parameters $\varphi$, AFR, as long as the specific heats $\bar{c}_{p}$ of both air and fuel. The actual value of the intake valve temperature $\theta_{2}$, and all the resulting parameters, can now be computed by the followed algorithm, also presented in Figure 4:

1. From the values of the temperature $\theta_{1}$ and of the specific water content $\omega_{1}$ before the point of water injection, we compute the corresponding specific enthalpy value $\underline{h}_{1}$, according to Equation (32).

2. From the values of the specific enthalpy $\underline{h}_{1}$ and of the intake pressure $p_{2}$, we compute the wet-bulb temperature $\theta_{\mathrm{wb}}$, so the minimum fresh mixture temperature that can be reached, in solving Equation (37).

3. Using Equation (38), we compute the equilibrium Water-Fuel Ratio $W_{F} R_{\text {eq }}$ corresponding to $\theta_{\mathrm{wb}}$ in Figure 3.

4. After a comparison between the actual Water-Fuel Ratio WFR and the one corresponding to a complete vaporisation of water $\mathrm{WFR}_{\text {eq }}$, we compute the actual intake temperature $\theta_{2}$ using Equation (34) if WFR $\leq \mathrm{WFR}_{\text {eq }}$, or Equation (42) otherwise. The required value of $\omega_{2}$ is obtained thanks to the actual WFR value used in Equation (8).

The same algorithm can also be used to optimise the fresh mixture temperature at the intake valve point, in ensuring at any time that $\mathrm{WFR}=\mathrm{WFR}_{\mathrm{eq}}$.

\subsection{Consequences on the amount of fresh mixture aspirated}

It is now possible to calculate the most important parameter of this study, the density of the gaseous fresh mixture at the intake valve point. We emphasize here on the gaseous part of the mixture because it is the only one that will play the role of a working fluid in the next strokes of the engine cycle. Furthermore, even if some liquid water is actually aspirated within the engine, its specific volume is so small in front the gaseous one, that the effective swept volume of the 


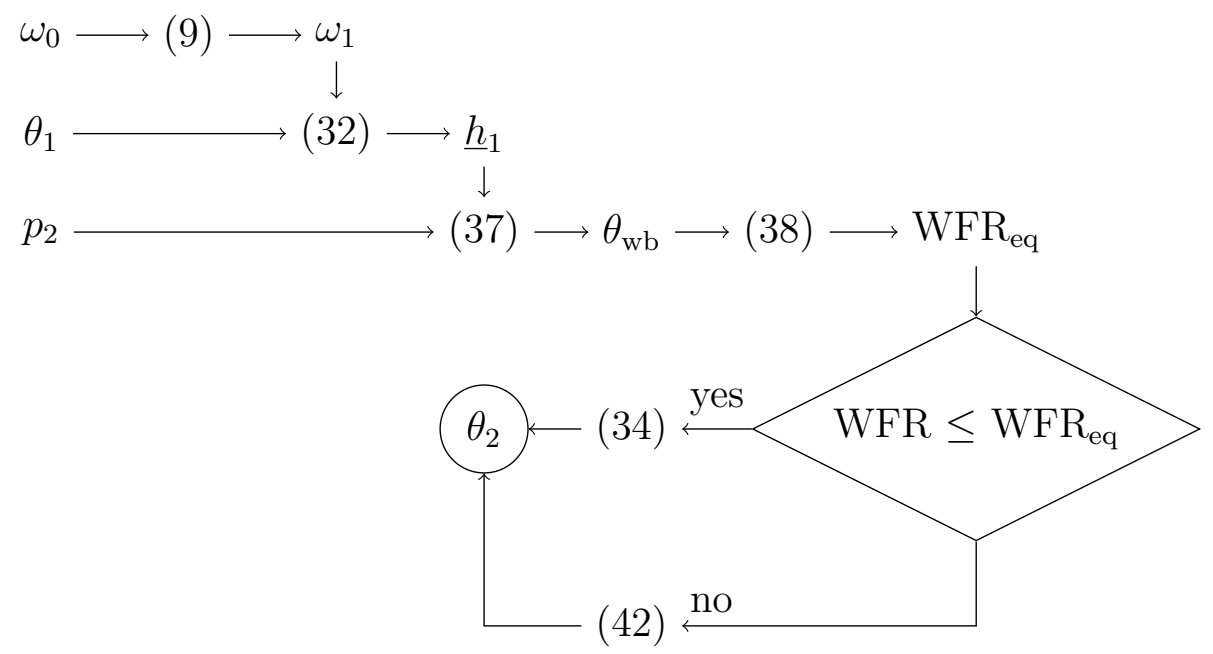

Figure 4: Graphical representation of the algorithm dedicated to the calculation of the fresh mixture temperature at the intake valve point $\theta_{2}$.

engine will not be affected. Thus, according to hypothesis $\mathrm{H} 8$ about the perfect nature of all the gases involved, the fresh mixture gaseous density at point 2 can be expressed as:

$$
\rho_{2}=\frac{m_{2}}{V_{d}}=\frac{p_{2}}{\underline{r} \cdot T_{2}}
$$

$T_{2}=\theta_{2}+273.15$ is the absolute fresh mixture temperature at the intake valve point, whom calculation process has just been detailed, and $\underline{r}$ is the fresh mixture specific constant given by:

$$
\underline{r}=\bar{r}_{\mathrm{dfm}}+\omega_{2} \cdot r_{w} \Leftrightarrow \bar{r}_{\mathrm{dfm}}=\frac{\varphi \cdot r_{\mathrm{fuel}}+\mathrm{AFR} \cdot r_{\mathrm{air}}}{\varphi+\mathrm{AFR}}
$$

Density $\rho_{2}$ is the one of the whole fresh mixture, including water vapour. The power eventually produced by the engine being primarily related to the amount of fuel aspirated - the required AFR value being ensured by the fuel injection system - we will rather consider the "fuel density" inside the fresh mixture, noted $\rho_{\text {fuel, } 2}$ and defined by:

$$
\rho_{\text {fuel }, 2}=\frac{m_{\text {fuel }, 2}}{V_{d}}=x_{\text {fuel }, 2} \cdot \rho_{2}=\frac{x_{\text {fuel }, 2} \cdot p_{2}}{\underline{r} \cdot T_{2}}
$$

With the mass fraction of fuel $x_{\text {fuel,2, }}$, from Equation (15), given by:

$$
x_{\text {fuel }, 2}=\frac{1}{\varphi+\mathrm{AFR} \cdot\left(1+\omega_{0}\right)+\mathrm{WFR}}
$$

$\varphi$ is replaced by 1 , the fuel being always injected before the start of the combustion process. $\rho_{\text {fuel }, 2}$ of Equation (45) is then the amount of fuel aspirated per the swept volume $V_{d}$.

It is now possible to assess the influence of the main parameters of the intake and water injection systems on the temperature and density of the fresh mixture at the intake valve point.

\section{Results and discussion}

In order to illustrate the interest of such analysis, we will consider in this paragraph some practical, although quite idealised, applications to different types of engines and gaseous and liquid fuels. 


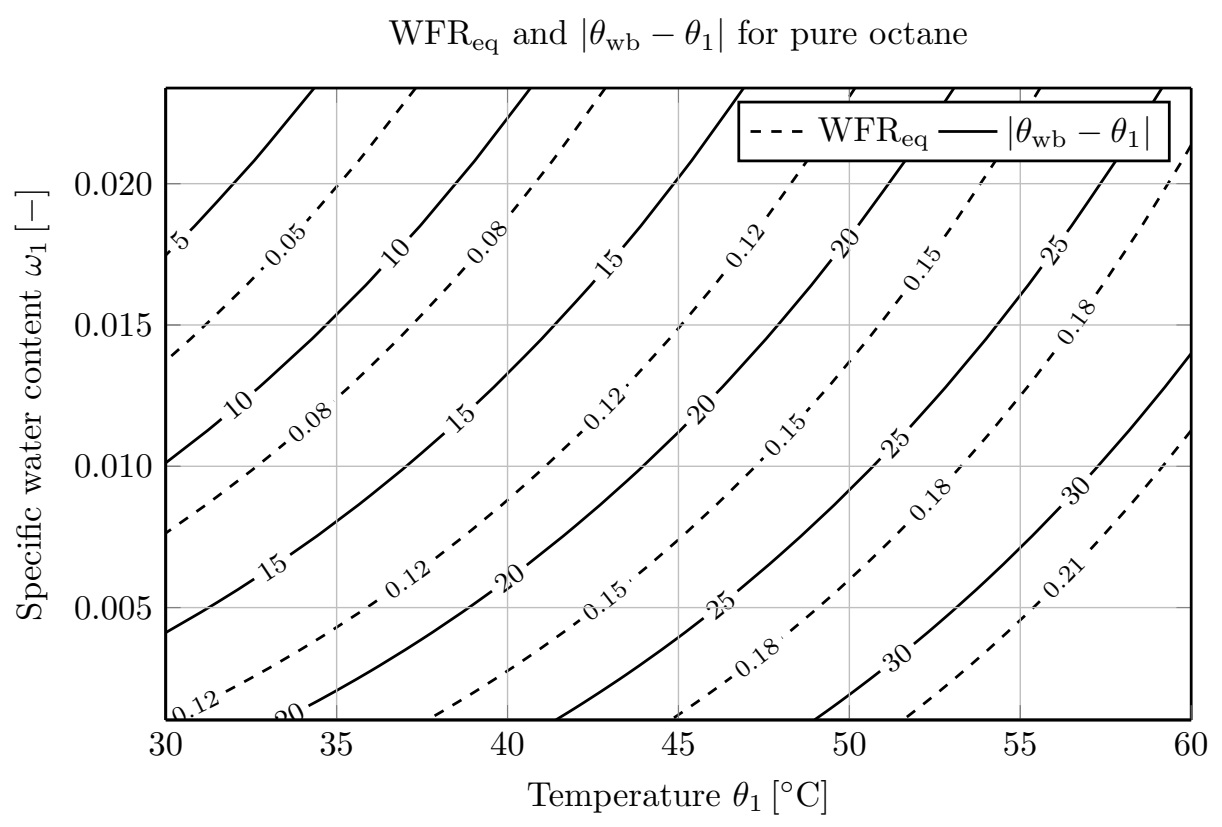

Figure 5: Equilibrium Water-Fuel Ratio $\mathrm{WFR}_{\mathrm{eq}}$ (dashed line) and resulting temperature drop $\left|\theta_{\mathrm{wb}}-\theta_{1}\right|$ (solid line) vs. intake manifold temperature $\theta_{1}$ and specific water content $\omega_{1}$, for a stoichiometric combustion $(\lambda=1)$ of pure octane $\left(\mathrm{C}_{8} \mathrm{H}_{18}\right)$ with an intake pressure $p_{2}=1$ bar.

\subsection{Spark ignited engine fed by pure octane}

Let us consider the case of a spark ignited internal combustion engine, so with $\varphi=1$, fed by pure octane $\left(\mathrm{C}_{8} \mathrm{H}_{18}\right)$, so with $\mathrm{AFR}_{\text {st }}=15.03$. The combustion process is supposed for now as stoichiometric, so with $\lambda=1$, and the intake pressure is for the moment such as $p_{2}=1$ bar. As explained previously, the equilibrium Water-Fuel Ratio $\mathrm{WFR}_{\text {eq }}$ and so the resulting wet-bulb temperature $\theta_{\mathrm{wb}}$ primary depend on "ambient related" parameters such as $\theta_{1}$ and $\omega_{1} \propto \omega_{0}$, according to Equation (9).

Such an influence is presented in Figure 5 with a range of intake manifold temperature given by $30^{\circ} \mathrm{C} \leq \theta_{1} \leq 60^{\circ} \mathrm{C}$, and a range of specific water content at the same point given by an ambient temperature $5^{\circ} \mathrm{C} \leq \theta_{0} \leq 30^{\circ} \mathrm{C}$ and an ambient relative humidity $0.2 \leq \phi_{0} \leq 0.9$.

It is clearly visible in the same figure that $W_{\text {eq }}$ is primarily influenced by the intake manifold temperature $\theta_{1}$ : the higher $\theta_{1}$, the higher WFR $_{\text {eq }}$ because of a higher value of the corresponding equilibrium pressure $p_{\text {eq }}$, and thus of the maximum specific water content $\omega_{\text {vap,eq }}$ (see Equation (11) or Figure 3). Hence, the hotter the surroundings, the larger the amount of liquid water to inject into the fresh mixture in order to reach $W_{F R}$. Although the specific water content $\omega_{1}$ has an opposite influence on the same parameter: the higher $\omega_{1}$, the lower the amount of water required to reach equilibrium, as expressed by Equation (13).

The influence of $\theta_{1}$ and $\omega_{1}$ on the attainable temperature drop is quite the same as for WFR $\mathrm{W}_{\text {eq }}$, i.e. $\left|\theta_{\mathrm{wb}}-\theta_{1}\right|$ evolves in the same way as $\theta_{1}$ and in the opposite way as $\omega_{1}$. This evolution is due to the approximate proportionality between this temperature difference and the WFR value, already highlighted by Equation (36).

Such a result has two very practical consequences on the use of the water injection process. When the ambient humidity increases - as for instance if the concerned engine operates in a tropical country - the attainable temperature drop decreases, because of the decreasing amount of injected water required to reach equilibrium between liquid water and steam. The same effect is obtained when temperature $\theta_{1}$ decreases - when the engine operates in cold country for instance - for the very same reason. In this last situation though, we can reasonably hope that 


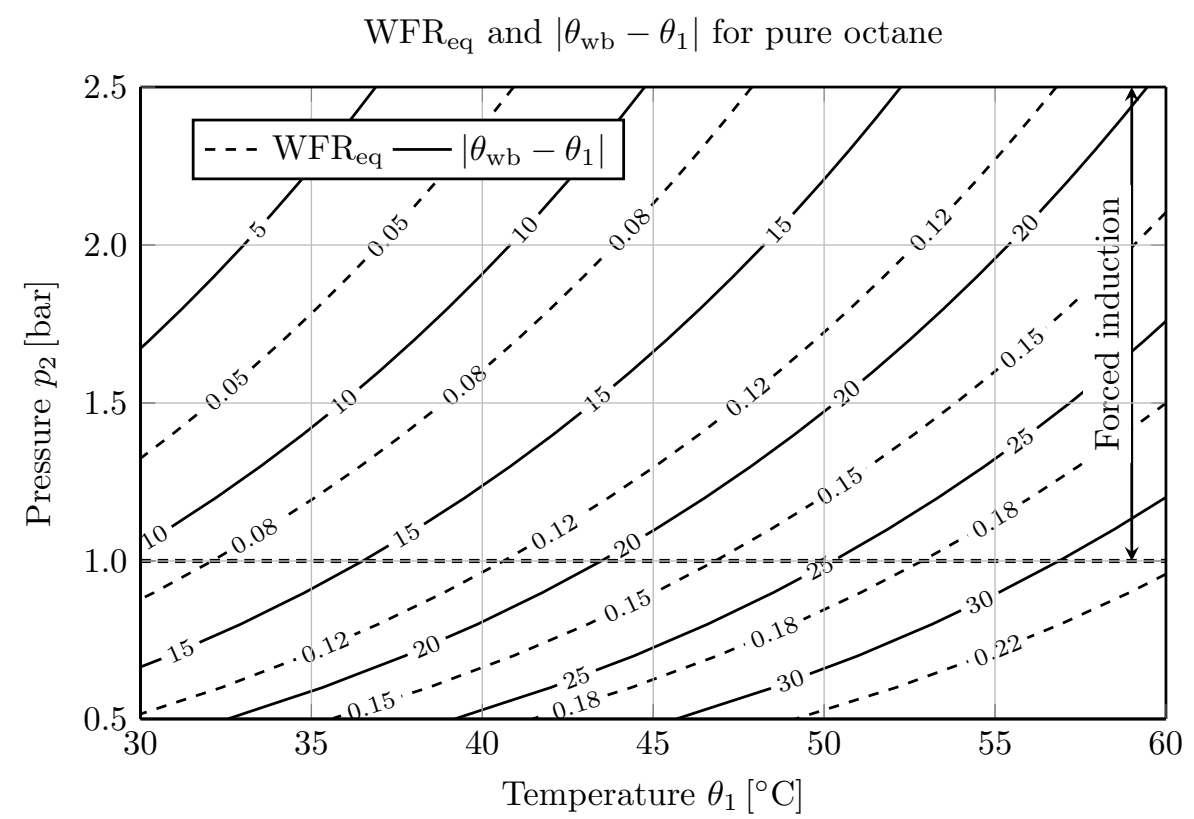

Figure 6: Equilibrium Water-Fuel Ratio $\mathrm{WFR}_{\text {eq }}$ (dashed line) and resulting temperature drop $\left|\theta_{\mathrm{wb}}-\theta_{1}\right|$ (solid line) vs. temperature $\theta_{1}$ and intake pressure $p_{2}$, for a stoichiometric combustion $(\lambda=1)$ of pure octane $\left(\mathrm{C}_{8} \mathrm{H}_{18}\right)$ with $\theta_{0}=20^{\circ} \mathrm{C}$ and $\phi_{0}=0.5$.

this detrimental effect would be partly compensated by the increasing density of ambient air, due to this low surrounding temperature.

In order to assess the interest of water injection on atmospheric engines operating at high altitudes, but also on engines using forced induction processes, the influence of the intake valve pressure $p_{2}=p_{1}$ - according to hypothesis $\mathrm{H} 7$ - on the same parameters is presented in Figure 6, with 0.5 bar $\leq p_{i} \leq 2.5$ bar. As it was already visible in Equation (11), the intake pressure $p_{2}$ has a similar influence as the specific water content $\omega_{1}$ : it decreases the temperature drop $\left|\theta_{\mathrm{wb}}-\theta_{1}\right|$ when increasing.

The amount of fresh mixture, and then of fuel finally aspirated into the engine, depends on $\theta_{2}$, and then of $\left|\theta_{2}-\theta_{1}\right|$, as well as $p_{2}$, as highlighted by Equation (45). The relative increase of fuel density $\rho_{\text {fuel, }, 2}$ regarding to an equivalent "dry" intake with $\mathrm{WFR}=0$, defined as:

$$
\frac{\Delta \rho_{\text {fuel }, 2}}{\rho_{\text {fuel }, 2}}=\frac{\rho_{\text {fuel }, 2}\left(\mathrm{WFR}=\mathrm{WFR}_{\mathrm{eq}}\right)-\rho_{\text {fuel }, 2}(\mathrm{WFR}=0)}{\rho_{\text {fuel }, 2}(\mathrm{WFR}=0)}
$$

is presented vs. $\theta_{1}$ and $p_{2}$ in Figure 7. The interest of water injection for fresh mixture density improvement clearly increases with the intake manifold temperature $\theta_{1}$ but decreases with pressure $p_{2}$. Even though $\theta_{1}$ increases until $80^{\circ} \mathrm{C}$, the relative increase of fuel aspirated is not higher than $10 \%$ for atmospheric engine, so with $p_{2} \simeq 1$ bar. For the sole purpose of fresh mixture density increase, and so for increasing the amount of fuel aspirated into an internal combustion engine, the indirect water injection seems, at first glance, of a moderated interest, at least when compared to usual forced induction strategies. As a matter of fact, increases of about $15 \%$ of brake torques experimentally observed by some authors [14] are then probably not only due to such increase of density, but also to the effect of water addition on the engine cycle itself.

The influence of the actual WFR value on the fuel density increase is presented in Figure 8 for three different values of the intake manifold temperature $\theta_{1}$ and for $p_{2}=1$ bar. The fresh mixture gaseous density, and so the amount of fuel eventually aspirated, is always maximum at equilibrium, so when $\mathrm{WFR}=\mathrm{WFR}_{\mathrm{eq}}$.

Because of the low concentration of fuel in the fresh mixture (AFR $\gg 1$ ), the Air-Fuel equivalent Ratio $\lambda$ has no practical influence of the relative increase of fuel density, as presented in 


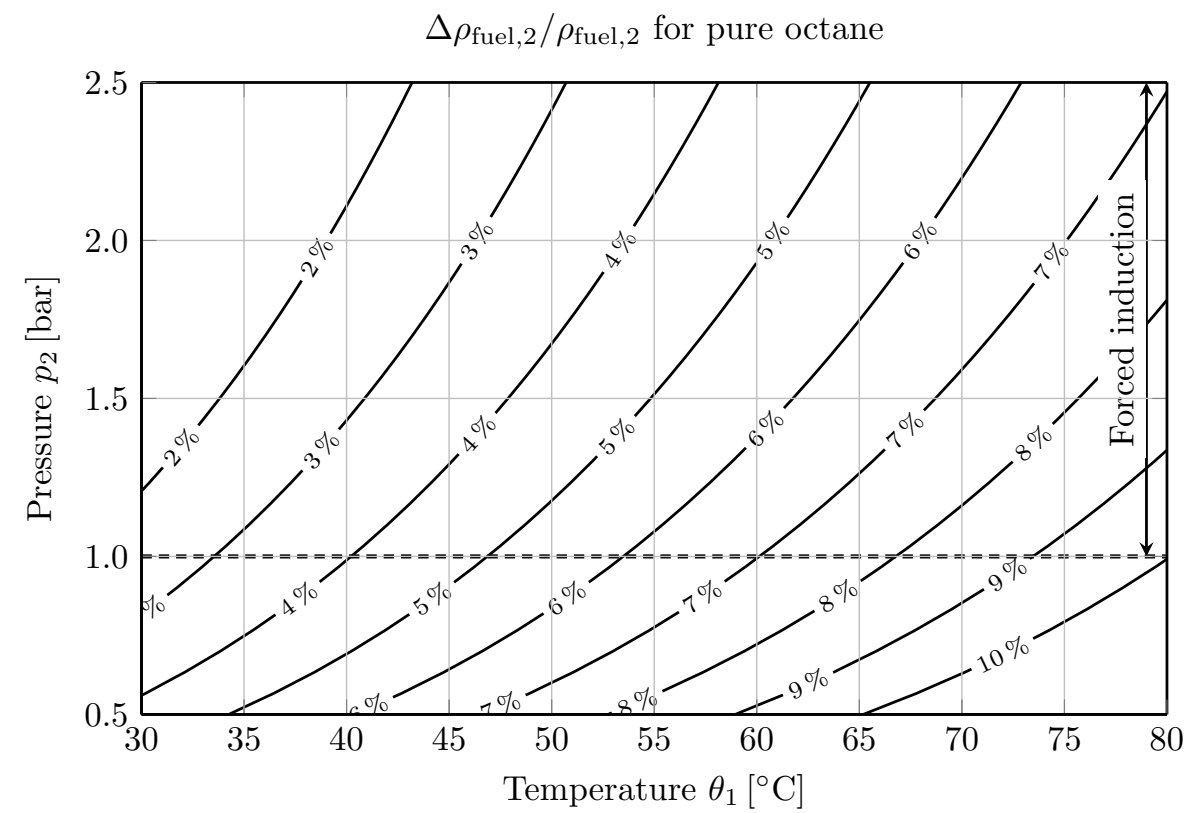

Figure 7: Relative fuel density increase regarding to a "dry" intake $\Delta \rho_{\text {fuel, } 2} / \rho_{\text {fuel, } 2}$, as defined by Equation (47), vs. $\theta_{1}$ and $p_{2}$, for a $\lambda=1$ and pure octane $\left(\mathrm{C}_{8} \mathrm{H}_{18}\right)$ with $\theta_{0}=20^{\circ} \mathrm{C}$ and $\phi_{0}=0.5$.

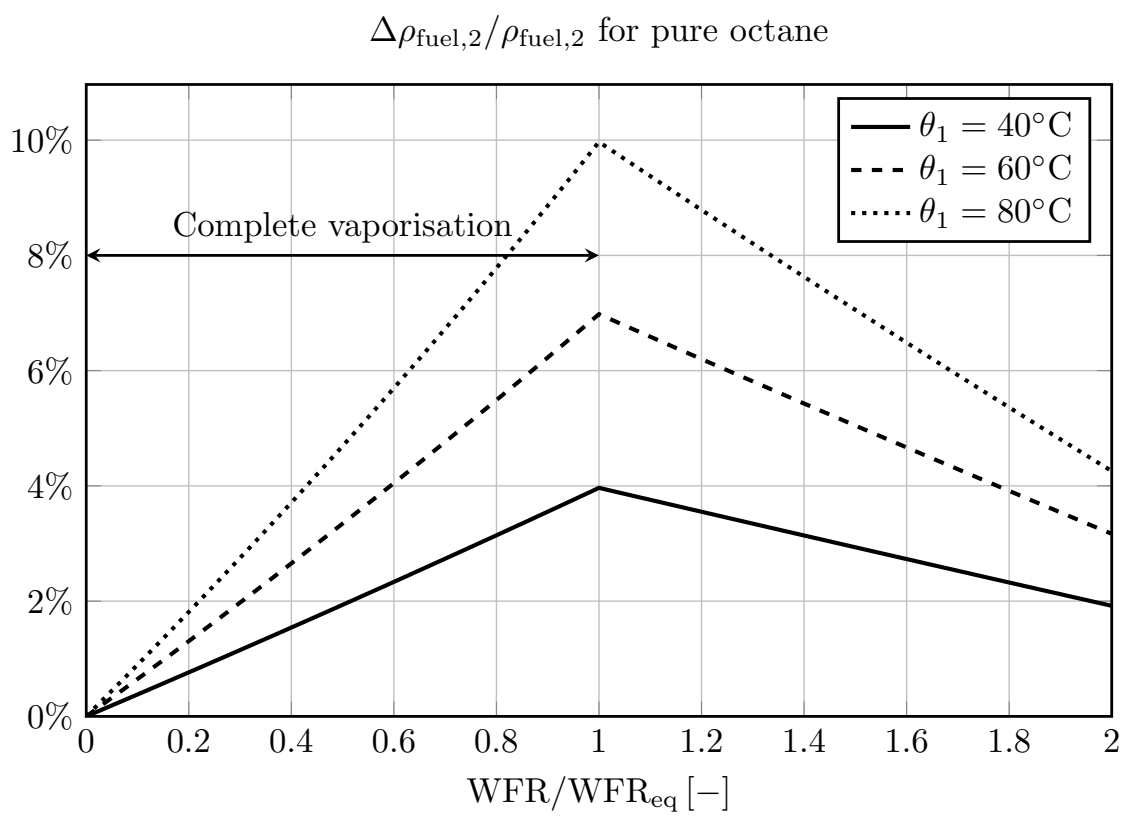

Figure 8: Relative fuel density increase regarding to a "dry" intake $\Delta \rho_{\text {fuel }, 2} / \rho_{\text {fuel, } 2}$ vs. WFR for $p_{2}=1$ bar, $\lambda=1$ and pure octane $\left(\mathrm{C}_{8} \mathrm{H}_{18}\right)$, with $\theta_{0}=20^{\circ} \mathrm{C}$ and $\phi_{0}=0.5$. 


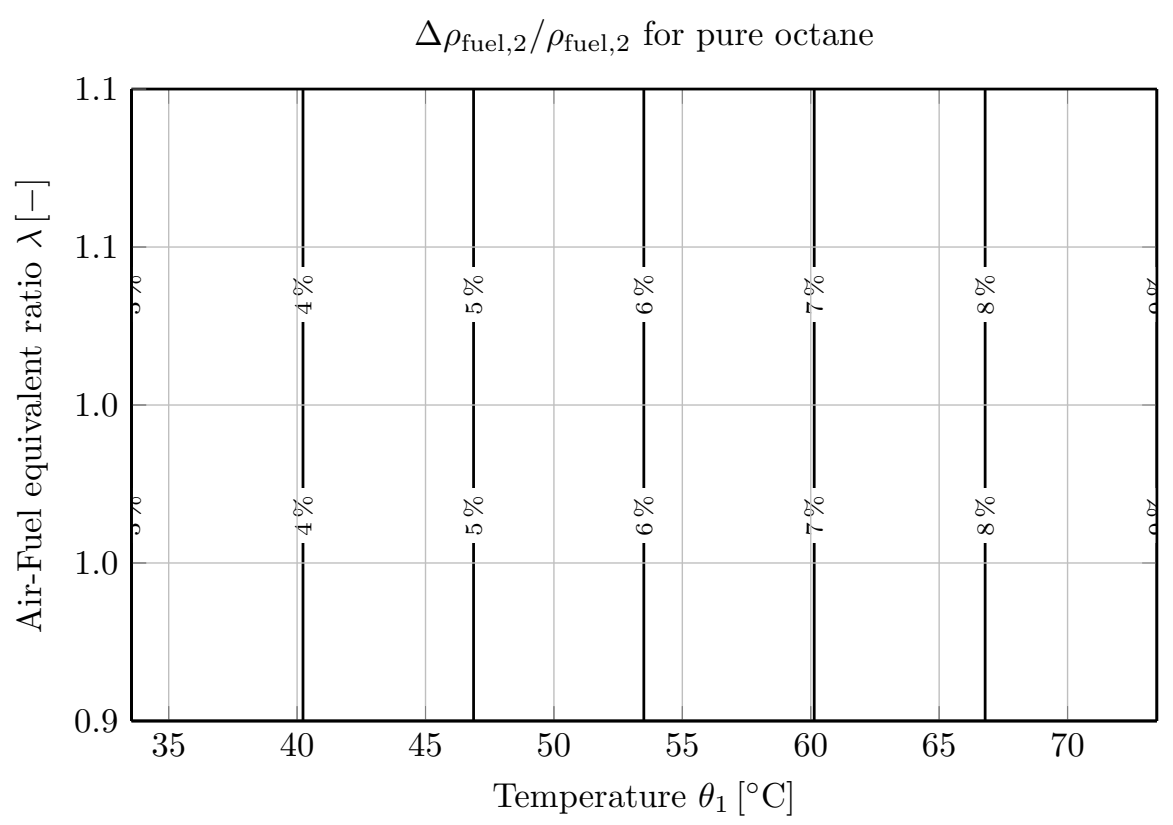

Figure 9: Relative fuel density increase regarding to a "dry" intake $\Delta \rho_{\text {fuel, } 2} / \rho_{\text {fuel, } 2}$ vs. $\theta_{1}$ and $\lambda$ for $p_{2}=1$ bar, pure octane $\left(\mathrm{C}_{8} \mathrm{H}_{18}\right), \theta_{0}=20^{\circ} \mathrm{C}$ and $\phi_{0}=0.5$.

Figure 9. This result will be of a great interest in future applications of such process, because optimizing the latter does not require to know the actual value of $\lambda$.

\subsection{Compression ignited engine fed by pure cetane}

According to the previous definitions, for a compression ignited engine fed by pure cetane $\left(\mathrm{C}_{16} \mathrm{H}_{34}\right)$, we have $\varphi=0$ and $\mathrm{AFR}_{\text {st }}=14.86$. Considering the same ranges of pressure and temperature as for the previous application, we obtain for example the values of $\mathrm{WFR}_{\mathrm{eq}}$ and $\left|\theta_{\mathrm{wb}}-\theta_{1}\right|$ vs. $\theta_{1}$ and $p_{2}$, presented in Figure 10. The comparison with the same results for octane, presented in Figure 6, shows no significant difference, emphasizing once again on the little importance of the fuel presence in the fresh mixture. Incidentally, it allows us to confirm the use of hypothesis $\mathrm{H} 4$ of page 3, dealing with the water injection occurring before or after the fuel one. Finally, the fresh mixture density increase vs. $\theta_{1}$ and $p_{2}$ is presented in Figure 11, and leads to the same conclusion about the insignificant presence of fuel within the fresh mixture.

\section{Conclusions}

The actual effect, and so the practical interest of water injection (WI) process for engines performance improvement, has been so far assessed in an experimental manner only. However interesting these results are, they are not relevant to anticipate the increase of performance we can expect from the setup of such process on an existing engine. Furthermore, the same results do not say anything about the specific consequences of WI on the intake stroke, on the compression stroke, or on the combustion process.

The results presented in this paper are a first try to split up the effect of WI on the different parameters of a given engine. They can also be used in a very practical manner, thanks to the python software specifically created for so, whom use is presented in $\S \mathrm{A}$, and freely available at github.com/avaudrey/Py-ICE-WaterInjection, in order to forecast the consequence of the setup of a WI system on an existing engine, and more specifically on the fresh mixture density increase hence produced. In the future, we can hope that the framework here presented shall be used for example for a "real-time" control of the amount of water injected in engines. 


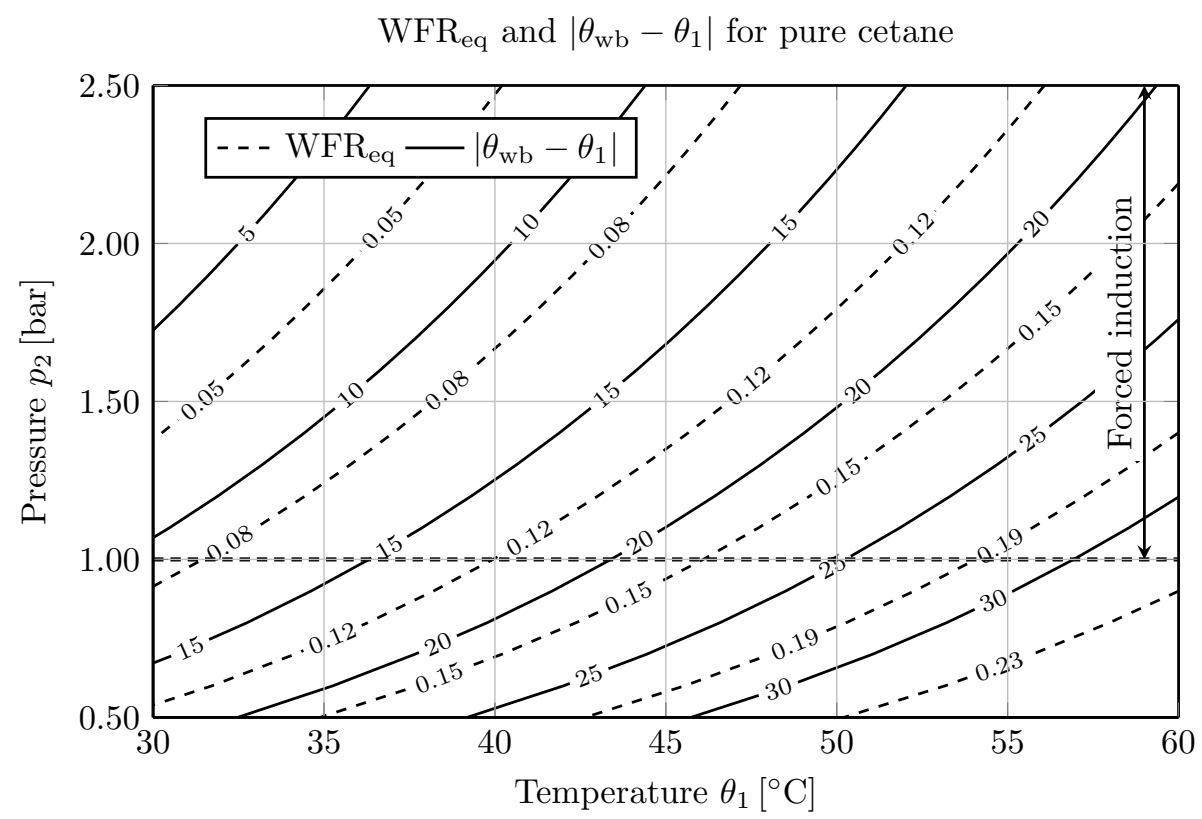

Figure 10: Equilibrium Water-Fuel Ratio $\mathrm{WFR}_{\mathrm{eq}}$ (dashed line) and resulting temperature drop $\left|\theta_{\mathrm{wb}}-\theta_{1}\right|$ (solid line) vs. temperature $\theta_{1}$ and intake pressure $p_{2}$, for a stoichiometric combustion $(\lambda=1)$ of pure cetane $\left(\mathrm{C}_{16} \mathrm{H}_{34}\right)$ with $\theta_{0}=20^{\circ} \mathrm{C}$ and $\phi_{0}=0.5$.

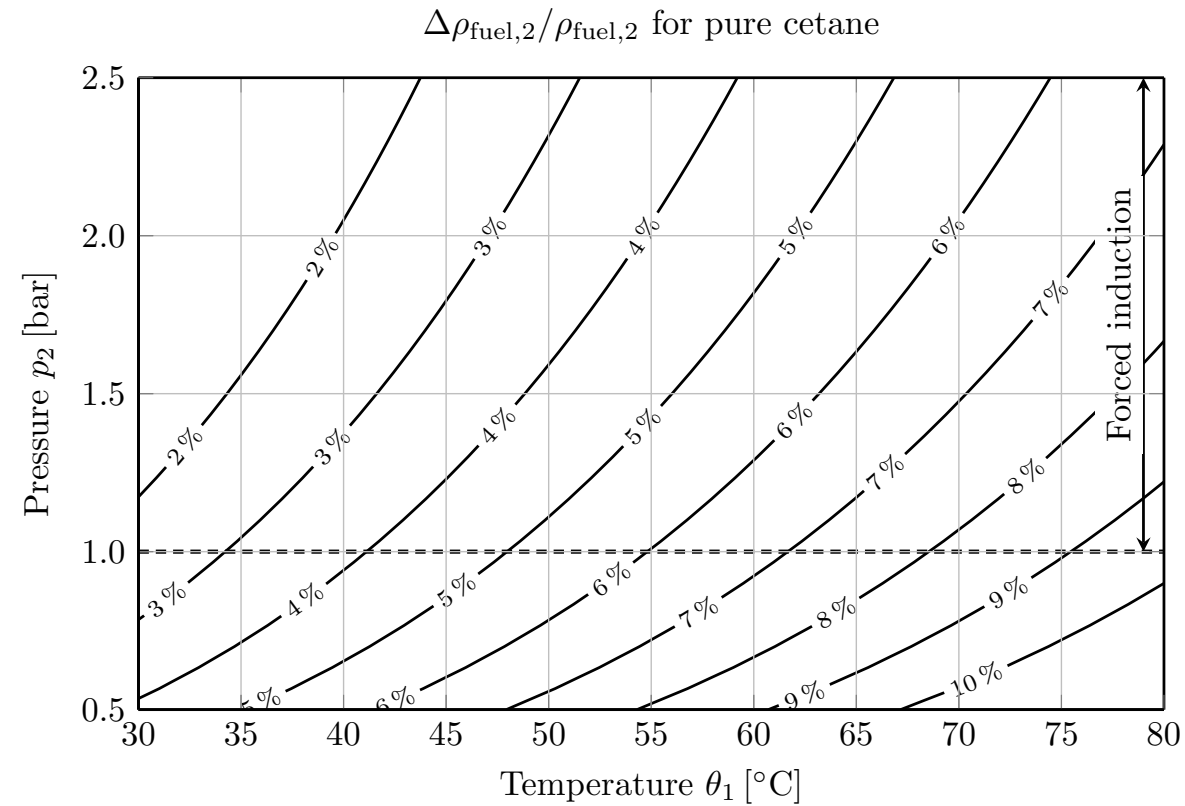

Figure 11: Relative fuel density increase regarding to a "dry" intake $\Delta \rho_{\text {fuel }, 2} / \rho_{\text {fuel, } 2}$ vs. $\theta_{1}$ and $p_{2}$, for a $\lambda=1$ and pure cetane $\left(\mathrm{C}_{16} \mathrm{H}_{34}\right)$ with $\theta_{0}=20^{\circ} \mathrm{C}$ and $\phi_{0}=0.5$. 
Such an approach deserves now to be extended on other parameters affecting the performance of internal combustion engines, i.e. firstly the mechanical work consumed by the compression stroke, and then the rest of the engine thermodynamic cycle.

\section{Acknowledgements}

The author would like to acknowledge the support of the PUCP Energy Laboratory for this research.

\section{Nomenclature}

$\begin{array}{llll} & \text { Notations } & & \text { Subscripts } \\ c_{p} & \text { Specific heat at cst pressure, }[\mathrm{J} /(\mathrm{kg} \cdot \mathrm{K})] & 0 & \text { Surroundings } \\ c_{V} & \text { Specific heat at cst volume, }[\mathrm{J} /(\mathrm{kg} \cdot \mathrm{K})] & \text { air } & \text { Dry air } \\ h & \text { Specific enthalpy, }[\mathrm{J} / \mathrm{kg}] & d & \text { Engine displacement or swept volume } \\ \ell & \text { Specific enthalpy of vaporisation, }[\mathrm{J} / \mathrm{kg}] & \text { eq } & \text { Equilibrium vapour pressure of water } \\ m & \text { Mass, }[\mathrm{kg}] & \mathrm{dfm} & \text { Dry fresh mixture } \\ \dot{m} & \text { Mass flow rate, }[\mathrm{kg} / \mathrm{s}] & \text { fuel } & \text { Fuel } \\ M & \text { Molar mass, }[\mathrm{kg} / \mathrm{mol}] & i & \text { Intake point } \\ n & \text { Amount of matter, }[\mathrm{mol}] & \text { liq } & \text { Liquid water } \\ p & \text { Pressure, }[\mathrm{bar}] & \text { st } & \text { Stoichiometric proportions } \\ r & \text { Specific constant of the gas, }[\mathrm{J} /(\mathrm{kg} \cdot \mathrm{K})] & \text { vap } & \text { Water vapour } \\ T & \text { Temperature, }[\mathrm{K}] & w & \text { Water } \\ V & \text { Volume, }\left[\mathrm{m}^{3}\right] & \text { wb } & \text { Wet-bulb temperature } \\ W & \text { Mechanical work, }[\mathrm{J}] & & \text { Acronyms } \\ x & \text { Mass fraction } & \text { AFR } & \text { Air-Fuel Ratio, see }(2) \\ & \text { Greek symbols } & \text { CI } & \text { Compression Ignited (Engines) } \\ \gamma & \text { Adiabatic index } & \text { HVAC } & \text { Heat, Ventilation and Air Conditioning } \\ \lambda & \text { Equivalent Air-Fuel Ratio } & \text { ICE } & \text { Internal Combustion Engines } \\ \phi & \text { Relative humidity } & \text { SI } & \text { Spark-Ignition (Engines) } \\ \varphi & \text { Fuel presence indicator function } & \text { UHC } & \text { Unburnt HydroCarbons } \\ \omega & \text { Specific water content, see }(5) & \text { WI } & \text { Water Injection } \\ \theta & \text { Relative temperature, in }\left[{ }^{\circ} \mathrm{C}\right] & \text { WFR } & \text { Water-Fuel Ratio, see (6) }\end{array}$

\section{A. The water injection python package}

\section{A.1. Introduction}

As previously explained, the results presented in this paper have been obtained thanks to a specifically created software, coded in python, and freely available - under the licence GNU GENERAL PUBLIC LICENSE ${ }^{4}$ Version 3 - at github.com/avaudrey/Py-ICE-WaterInjection. This package uses two python scientific libraries called numpy (numpy.org) and scipy (scipy.org). Any help, advice or contribution is obviously welcome in order to improve or extend the performance of this code.

We will now briefly present how to use such a package, for example for the practical assessment of a possible water injection process on an existing engine. We will assume that the reader knows more or less what a version control system is - here we use git (git-scm.com) - and is familiar with the basics of oriented object programming. No real proficiency in python is required to use this package, which can be called from an external *.py file or from a command line, in pure python or using ipython or jupyter (ipython.org) [41].

${ }^{4}$ gnu.org/licenses/gpl-3.0.en.html 


\section{A.2. Creation of a fresh mixture}

Basically, all the calculations can be done using only one python object, of the FreshMixture class. Any use of such a package must then begin with the creation of a new fresh mixture, as presented in Listing 1.

Listing 1: Instantiation of an object from the FreshMixture class, called here mixture.

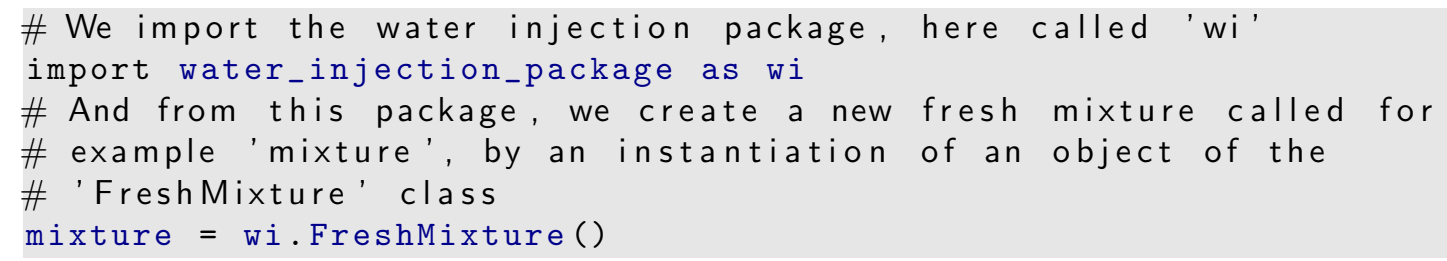

Once the mixture object has been created, we can now select a specific fuel, here for example neat ethanol $\left(\mathrm{C}_{2} \mathrm{H}_{5} \mathrm{OH}\right)$, as presented in line 4 of Listing 2 . The only other physical properties required for this fuel is the value of specific heat at constant pressure $c_{p}$, in $[\mathrm{J} /(\mathrm{kg} \cdot \mathrm{K})]$.

Listing 2: A new fuel can be considered, from its chemical composition of the type $\mathrm{C}_{x} \mathrm{H}_{y} \mathrm{O}_{z} \mathrm{~N}_{u} \mathrm{~S}_{w}$ and from its specific heat at constant pressure value $c_{p}$.

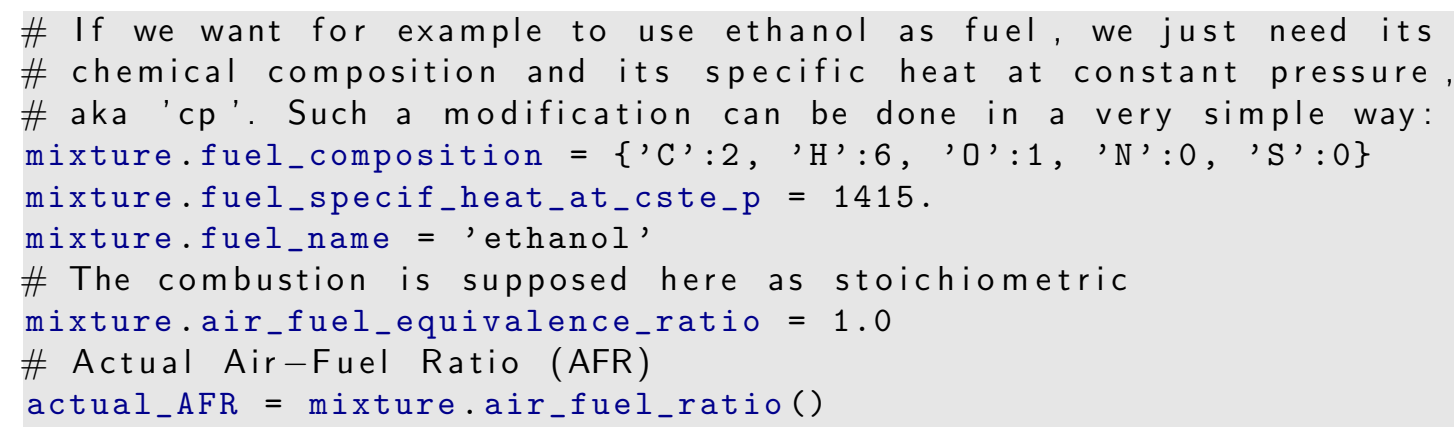

If the air_fuel_equivalence_ratio, so far noted $\lambda$, is entered, as in line 8 of Listing 2 , a method called air_fuel_ratio() can be directly called in order to compute the actual AFR value, as presented in line 10. All attributes and methods included in this object are presented in Figure 12.

\section{A.3. Other parameters and first results}

The system surroundings and intake parameters can also be chosen using specific attributes, as presented in the same figure and in Listing 3.

Listing 3: The ambient and intake parameters can be entered in the same very simple way, and can lead to calculations of the equilibrium Water-Fuel Ratio (WFR eq of Equation (13)) and of the corresponding wet-bulb temperature.

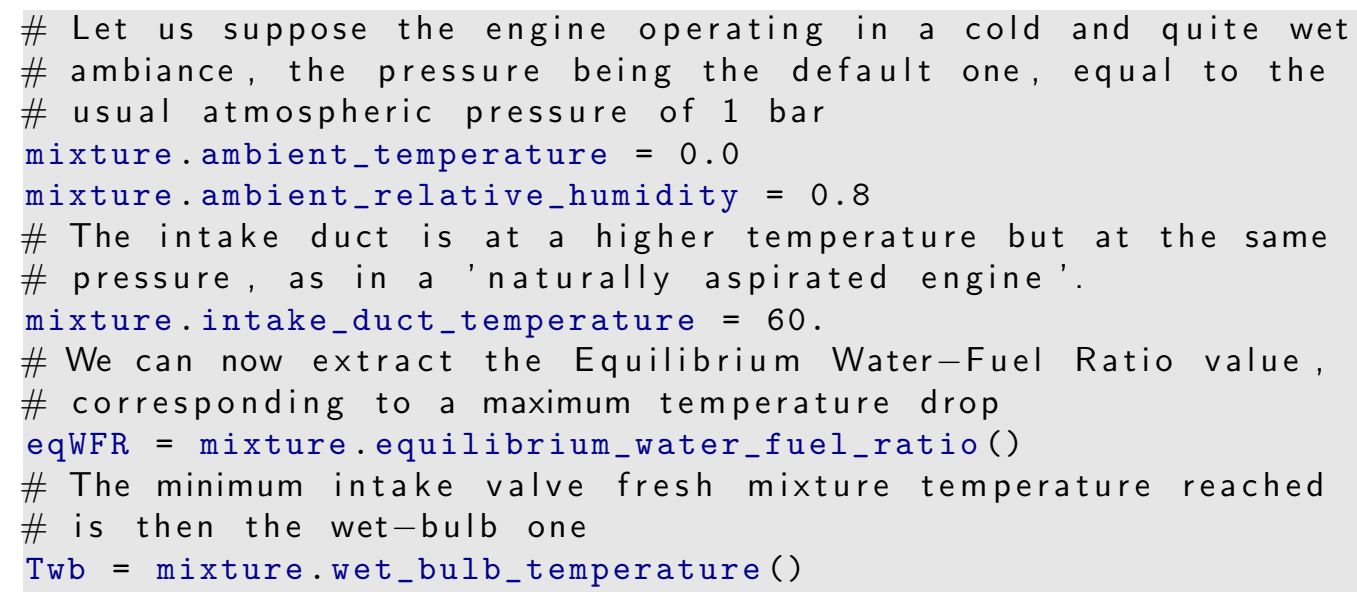


The main interesting results of such analysis, as for instance the equilibrium Water-Fuel Ratio or the corresponding wet-bulb temperature, can then be calculated in a very simple manner, as presented at the end of Listing 3. It is also possible to adjust the actual Water-Fuel Ratio value and to study its consequences on different parameters of the engine, as for example the fresh mixture fuel density at the intake valve point, defined by Equation (45), using the intake_valve_fuel_density() method.

\section{References}

[1] A. Schäfer, J. B. Heywood, and M. A. Weiss. Future fuel cell and internal combustion engine automobile technologies: A 25-year life cycle and fleet impact assessment. Energy, 31(12):2064-2087, 2006. doi:10.1016/j.energy.2005.09.011.

[2] C. Berggren and T. Magnusson. Reducing automotive emissions-The potentials of combustion engine technologies and the power of policy. Energy Policy, 41:636-643, 2012. doi:10.1016/j.enpol.2011.11.025.

[3] Use of Energy in the United States Explained - Energy Use for Transportation. Technical report, United States Energy Information Administration, October 2016. URL http:// www.eia.gov/energyexplained/?page=us_energy_transportation.

[4] A. M. K. P. Taylor. Science review of internal combustion engines. Energy Policy, 31(12): 4657-4667, 2008. doi:10.1016/j.enpol.2008.09.001.

[5] F. Payri, J. M. Luján, C. Guardiola, and B. Pla. A Challenging Future for the IC Engine: New Technologies and the Control Role. Oil \& Gas Science and Technology, 70(1):15-30, 2015. doi:10.2516/ogst/2014002.

[6] F. Hoppe, M. Thewes, H. Baumgarten, and J. Dohmen. Water injection for gasoline engines: Potentials, challenges, and solutions. International Journal of Engine Research, 17(1):8696, 2016. doi:10.1177/1468087415599867.

[7] H. Shyam Prasad, J. Gonsalvis, and V. S. Vijay. Effect of Introduction of Water into Combustion Chamber of Diesel Engines - A Review. Energy and Power, 5(1A):28-33, 2015. doi:10.5923/c.ep.201501.06.

[8] R.-H. Chen, L.-B. Chiang, M.-H. Wu, and T.-H. Lin. Gasoline displacement and NOx reduction in an SI engine by aqueous alcohol injection. Fuel, 89:604-610, 2010. doi:10.1016/j.fuel.2009.07.015.

[9] A. B. Dempsey, B. D. Adhikary, S. Viswanathan, and R. D. Reitz. Reactivity Controlled Compression Ignition Using Premixed Hydrated Ethanol and Direct Injection Diesel. Journal of Engineering for Gas Turbine and Power, 134(8):082806, June 2012. doi:10.1115/1.4006703.

[10] J.-K. Wang, J.-L. Li, M.-H. Wu, and R.-H. Chen. Reduction of Nitric Oxide Emission from a SI Engine by Water Injection at the Intake Runner. In ASME 2009 International Mechanical Engineering Congress and Exposition, pages 335-340, Lake Buena Vista, Florida, USA, November 13-19 2009. doi:10.1115/IMECE2009-12517.

[11] I. Cesur, A. Parlak, V. Ayhan, B. Boru, and G. Gonca. The effects of electronic controlled steam injection on spark ignition engine. Applied Thermal Engineering, 55:61-68, 2013. doi:10.1016/j.applthermaleng.2013.02.020. 
[12] A. Mohan, P. K. Chidambaram, A. Suryan, and H. D. Kim. Thermo-fluid dynamic analysis of wet compression process. Journal of Mechanical Science and Technology, 30(12):54735483, 2016. doi:10.1007/s12206-016-1115-4.

[13] A. Boretti. Water injection in directly injected turbocharged spark ignition engines. Applied Thermal Engineering, 52(1):62-68, 2013. doi:10.1016/j.applthermaleng.2012.11.016.

[14] D. Busuttil and M. Farrugia. Experimental Investigation on the Effect of Injecting Water to the Air to Fuel Mixture in a Spark Ignition Engine. MM (Modern Machinery) Science Journal, 1:585-590, March 2015. doi:10.17973/MMSJ.2015_03_201510.

[15] R. J. Brun, H. Lowell Olsen, and C. D. Miller. End zone water injection as a means of suppressing knock in a spark-ignition engine. Technical report, National Advisory Committee for Aeronautics, Report No. E4I27, Aircraft Engine Research Laboratory, Cleveland, Ohio, 1944.

[16] P. Lappas. Burn-rate and knock reduction in the spark ignition engine. International Journal of Energy Research, 20(9):829-838, 1996. doi:10.1002/(SICI)1099114X(199609)20:9<829::AID-ER203>3.0.CO;2-L.

[17] B. Peters and R. Stebar. Water-gasoline fuels-their effect on spark ignition engine emissions and performance. SAE Technical Paper, 760547, 1976. doi:10.4271/760547.

[18] J. Harrington. Water addition to gasoline-effect on combustion, emissions, performance, and knock. SAE Technical Paper, 820314, 1982. doi:10.4271/820314.

[19] K. Tsao, C. Wang, and E. Miller. Performance of gasoline-water fuel in a modified si engine. SAE Technical Paper, 841399, 1984. doi:10.4271/841399.

[20] S. Brusca and R. Lanzafame. Water injection in ic - si engines to control detonation and to reduce pollutant emissions. SAE Technical Paper, 2003-01-1912, 2003. doi:10.4271/200301-1912.

[21] J. B. Heywood. Internal Combustion Engine Fundamentals. McGraw-Hill, 1988.

[22] D. Hountalas, G. Mavropoulos, and T. Zannis. Comparative Evaluation of EGR, Intake Water Injection and Fuel/Water Emulsion as NOx Reduction Techniques for Heavy Duty Diesel Engines. SAE Technical Paper, 2007-01-0120, 2007. doi:10.4271/2007-01-0120.

[23] F. L. Dryer. Water addition to practical combustion systems - concepts and applications. Proceedings of the Combustion Institute, 16(1):279-295, 1977. doi:10.1016/S00820784(77)80332-9.

[24] J. Parley Wilson. Effects of Water Injection and Increased Compression Ratio in a Gasoline Spark Ignition Engine. MSc Thesis, University of Idaho, 2011. URL http://digital.lib. uidaho.edu/cdm/ref/collection/IR/id/11.

[25] A. Sarvi, P. Kilpinen, and R. Zevenhoven. Emissions from large-scale medium-speed diesel engines: 3. influence of direct water injection and common rail. Fuel Processing Technology, 90:222-231, 2009. doi:10.1016/j.fuproc.2008.09.003.

[26] M. R. Rowe and G. T. Ladd. Water injection for aircraft engines. SAE Technical Paper, 460192, 1946. doi:10.4271/460192.

[27] R. Smith. Alpine 83 Renault: The Development of the Revolutionary Turbo F1 Car, 1968 to 1979. Veloce Publishing Ltd, 2008. 
[28] F. Bedford, C. Rutland, P. Dittrich, A. Raab, and F. Wirbeleit. Effects of Direct Water Injection on DI Diesel Engine Combustion. SAE Technical Paper, 2000-01-2938, 2000. doi:10.4271/2000-01-2938.

[29] J. Kim, H. Park, C. Bae, M. Choi, and Y. Kwak. Effects of water direct injection on the torque enhancement and fuel consumption reduction of a gasoline engine under high-load conditions. International Journal of Engine Research, 17(7):795-808, 2016. doi:10.1177/1468087415613221.

[30] D. Woodyard. Pounder's Marine Diesel Engines and Gas Turbines, $8^{\text {th }}$ Edition. Elsevier, 2004.

[31] Sam Sheehan. BMW M4 GTS's water injection system to feature on other cars from 2019, 2016. URL https://www.autocar.co.uk/car-news/industry/ bmw-m4-gtss-water-injection-system-feature-other-cars-2019.

[32] ASHRAE Handbook: Fundamentals, chapter 6: Psychrometrics. American Society of Heating, Refrigerating and Air-Conditioning Engineers, 2001.

[33] R. Richards. Diesel Engine Reference Book, $2^{\text {nd }}$ Edition, chapter 25: Dual fuel engines, pages 614-630. Butterworth-Heinemann, 1999.

[34] A. Modak and L. Caretto. Engine cooling by direct injection of cooling water. SAE Technical Paper, 700887, 1970. doi:10.4271/700887.

[35] W. Weatherford and R. Quillian. Total cooling of piston engines by direct water injection. SAE Technical Paper, 700886, 1970. doi:10.4271/700886.

[36] S. Lestz, W. Meyer, and C. Colony. Emissions from a direct-cylinder water-injected sparkignition engine. SAE Technical Paper, 720113, 1972. doi:10.4271/720113.

[37] R. Lanzafame. Water injection effects in a single-cylinder cfr engine. SAE Technical Paper, 1999-01-0568, 1999. doi:10.4271/1999-01-0568.

[38] C. F. Bohren and B. A. Albrecht. Atmospheric Thermodynamics. Oxford University Press, New York, 1998.

[39] R. W. Hyland and A. Wexter. Formulations for the thermodynamic properties of the saturated phases of $\mathrm{H}_{2} \mathrm{O}$ from $173.15 \mathrm{~K}$ to $473.15 \mathrm{~K}$. ASHRAE Transactions, 89:500-519, 1983.

[40] National Insitute of Standards and Technology (NIST). URL http://webbook.nist.gov/.

[41] F. Pérez and B. E. Granger. IPython: a system for interactive scientific computing. Computing in Science and Engineering, 9(3):21-29, May 2007. doi:10.1109/MCSE.2007.53. 


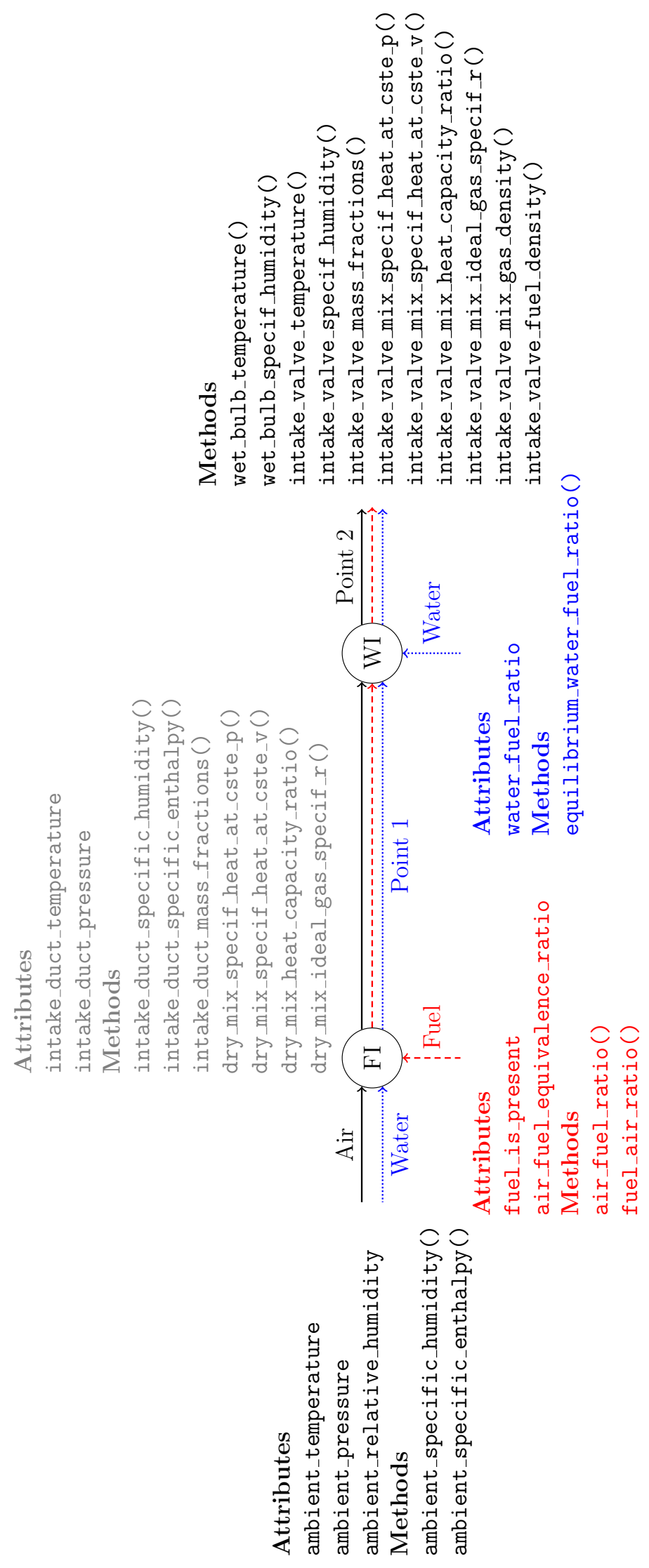

Figure 12: Structure of the FreshMixture class, with its attributes and methods related to specific parts of the complete engine intake system. 